\title{
Modelling the distribution and quality of sand and gravel resources in 3D: a case study in the Thames Basin, UK.
}

\author{
Mee K ${ }^{\mathrm{a}, \mathrm{b}}$, Marchant BP ${ }^{\mathrm{a}}$, Mankelow JM ${ }^{\mathrm{a}}$, Bide TP ${ }^{\mathrm{a}}$ \\ ${ }^{\text {a }}$ British Geological Survey, Environmental Science Centre, Keyworth, Nottingham, NG12 5GG, UK \\ ${ }^{\mathrm{b}}$ Corresponding author: Email: katy@bgs.ac.uk, Telephone: +44 (0)1159363100
}

Keywords: 3D model; mineral resource model; additive log-ratio transform; linear model of coregionalization

\section{Acknowledgements}

This paper is published with the permission of the Executive Director of the British Geological Survey (NERC). It was funded by BGS National Capability funding from NERC. The authors would like to thank Dr. David Malone, Andy Kingdon, John Williams and another anonymous reviewer, for constructive reviews which have greatly improved this manuscript. Contains Ordnance Survey Data $\mathbb{C}$ Crown copyright and database rights [2018]. Ordnance Survey Licence no. 100021290. Maps were created using ArcGIS ${ }^{\circledR}$ software by Esri. ArcGIS ${ }^{\circledR}$ and ArcMap ${ }^{\text {TM }}$ are the intellectual property of Esri and are used herein under license. Copyright (C) Esri. All rights reserved. For more information about Esri ${ }^{\circledR}$ software, please visit www.esri.com.

\begin{abstract}
Three-dimensional (3D) models are often utilised to assess the presence of sand and gravel deposits. Expanding these models to provide a better indication of the suitability of the deposit as aggregate for use in construction would be advantageous. This, however, leads to statistical challenges. To be effective, models must be able to reflect the interdependencies between different criteria (e.g. depth to deposit, thickness of deposit, ratio of mineral to waste, proportion of 'fines') as well as the inherent uncertainty introduced because models are derived from a limited set of boreholes in a study region.

Using legacy borehole data collected during a systematic survey of sand and gravel deposits in the UK, we have developed a 3D model for a $2400 \mathrm{~km}^{2}$ region close to Reading, southern England. In developing the model, we have reassessed the borehole grading data to reflect modern extraction criteria and explored the most suitable statistical modelling technique. The additive log-ratio transform and the linear model of coregionalization have been applied, techniques that have previously been used to map soil texture classes in two dimensions, to assess the quality of sand and gravel deposits in the area. Application of these statistical techniques lead to a model which can be used to generate thousands of plausible realizations of the deposit which fully reflect the extent of model uncertainty. The approach offers potential to improve regional scale mineral planning by providing an enhanced understanding of sand and gravel deposits and the extent to which they meet current extraction criteria.
\end{abstract}

\section{Introduction}

\subsection{Background}

The construction industry is a critical sector of the UK economy contributing, in 2016, £102 billion in economic output (gross value added), $6.2 \%$ of the total [1]. Aggregates, such as crushed rock, sand, and gravel, are the most commonly used construction minerals in the UK, meaning that maintenance of an adequate and reliable supply of these materials is essential. To ensure this demand is met, aggregates will have to be provided, from indigenous production, for the foreseeable future.

Minerals can only be worked where they occur. With increased pressure on land use in the UK, there is a need to ensure that these resources are not needlessly sterilised by other development, potentially leaving insufficient supplies for future generations. Knowledge of both the distribution of mineral resources and, increasingly, their quality and suitability as aggregates, is essential to enable land-use planning authorities to make sustainable decisions [2].

Strategic mineral resource estimation has been carried out for many decades, but has changed considerably over the past 50 years due to advancements in computer power, software capability and numerical and geostatistical modelling. Simple mathematical models were applied to resource estimation during the 1950s and 1960s, with the first mine planning software packages introduced in the late 1970s [3]. Sophisticated and specialised geostatistical modelling packages are now commonplace in mineral resource estimation, and commercial mining companies can carry out a cost-benefit analysis at any stage during project development to determine whether a new drilling programme can further reduce the uncertainty in their models [4].

Many national geological survey organisations (GSOs) have gradually digitised their traditional two-dimensional (2D) geological maps and begun to produce three-dimensional (3D) subsurface models, which describe the geology at depth 
[5-7]. Increasingly, GSOs are using 3D modelling techniques, similar to those already used by mining companies at sitescale, to develop national and regional scale resource estimations [8-11]. These 3D subsurface models can be attributed with a range of hydrogeological, mineralogical and engineering properties with the aim of identifying broad trends and enabling improved decision making [7-8].

There are numerous 3D modelling approaches that could be adopted, depending on the geologic condition, available resources and intended use of the resulting models. A number of studies have used geophysical techniques, such as seismic refraction [12-14] georadar [15] and electrical resistivity tomography [16-18], to delineate sand and gravel deposits. Similarly, numerous geostatistical techniques [8-9, 19-22] and modelling software, such as Petrel [12], GOCAD-SKUA $[8,22]$ and GSI3D [23-25], have also been used in previous studies. In central Glasgow, UK, stochastic modelling has been used for predicting glacial and fluvial deposits to better represent the uncertainty and complexity of the lithological variations [8]. The authors suggested that, whilst traditional lithostratigraphic modelling can bring together expertise of both geologists and known geological relationships, it is often time consuming, requiring resources over many years which may be impractical for many current or planned urban redevelopment schemes [8].

The aim of the current study was to investigate the suitability of modern 3D modelling techniques for enhancing existing knowledge of not only the quantity but also the quality of sand and gravel deposits in England, using legacy borehole data. We adopt a technique that both reflects the interdependencies between different extraction criteria and the uncertainty introduced into a model where only limited borehole data is available

\subsection{Mineral resource information for the UK}

The British Geological Survey (BGS) has been producing mineral resource data for many years to aid land-use planning and is the major UK national provider of spatial and statistical minerals information. For sand and gravel, this was in the form of Mineral Assessment Reports (MARs), which drew heavily from a substantial dataset collected between 1971 and 1990 [26]. Data were collected via a systematic survey of sand and gravel deposits across England, Scotland and Wales with the results published in 150 MARs and associated maps, approximately 12500 detailed borehole interpretations and more than 54000 sand and gravel grain size distributions (grading analyses).

More recently (1995 - 2004), the BGS has published mineral resource maps, defined by local planning area, for much of the UK, which combine mineral resource, environmental and other land-use information [27]. These mineral resource maps depict:

- The geological distribution of all onshore mineral resources;

- The location of active mineral extraction sites;

- The extent of current and former mineral planning permissions and licenses for coal extraction; and

- The extent of selected national (National Parks (NPs), Areas Of Outstanding Natural Beauty (AONBs), Sites of Special Scientific Interest (SSSIs), National Nature Reserves (NNRs), Scheduled Ancient Monuments) and international (Special Protection Areas (SPA), Special Areas of Conservation (SAC), Ramsar sites) landscape and nature-conservation designations.

The primary objective for producing the maps was to provide baseline data on mineral resource location and extent that can be utilised by land-use planning authorities in the preparation of Mineral Development Plan Documents. However, there is now an increasing need for provision of information on the properties of the mineral resources; for example, identification of areas of sand and gravel which are likely to contain coarse sand and are therefore suitable for use as concreting aggregate. These areas should become a primary focus for safeguarding from other forms of development which might otherwise sterilise future access to the mineral.

A systematic survey and borehole sampling programme of the intensity of that undertaken by the BGS between 1971 and 1990 has never been repeated and is unlikely to be in the foreseeable future. As such, the borehole data and, in particular, the large volume of sand and gravel grading analyses, remain the best dataset available for interpreting the quality of sand and gravel within a potential mineral resource.

\subsection{Mineral resource identification}

A mineral resource is defined as a natural concentration or occurrence of material of intrinsic economic interest in or on the Earth's crust in such form, quality and quantity that there are reasonable prospects for eventual economic extraction [28]. Definitions of economic interest change over time as markets decline or expand, product specifications change, recovery technology is improved or more competitive sources become available.

When the mineral resource maps for the original MARs were developed, criteria relevant to the economics and limitations of extraction technology which existed at the time were applied to the data in order to identify viable deposits. These included certain thresholds of overburden to mineral thickness ratios, depth to and thickness of the deposit and the percentage of fines (particles $<0.063 \mathrm{~mm}$ in size) (Table 1). 
Table 1 Extraction criteria relevant when the MAR Mineral Assessment Reports were produced (old criteria), compared to modern day criteria drawn-up through discussion and consultation with the minerals industry (new criteria).

\begin{tabular}{|c|c|c|}
\hline \multirow{2}{*}{ Original MAR Criteria } & \multicolumn{2}{|c|}{ New Criteria } \\
\hline & Category A deposit & Category B deposit \\
\hline $\begin{array}{l}\text { The deposit should average at least } 1 \\
\text { metre in thickness. }\end{array}$ & $\begin{array}{l}\text { The deposit should average at least } \\
2 \mathrm{~m} \text { thickness. }\end{array}$ & $\begin{array}{l}\text { The deposit should average at } \\
\text { least } 2 \mathrm{~m} \text { thickness. }\end{array}$ \\
\hline $\begin{array}{l}\text { Ratio of overburden to sand and gravel } \\
\text { should be no more than } 3: 1 \text {. }\end{array}$ & $\begin{array}{l}\text { Ratio of overburden to mineral should } \\
\text { not exceed } 1: 1 \text {. }\end{array}$ & $\begin{array}{l}\text { Ratio of overburden to mineral } \\
\text { should not exceed } 2: 1 \text {. }\end{array}$ \\
\hline $\begin{array}{l}\text { The proportion of fines (particles } \\
\text { passing } 0.063 \mathrm{~mm} \text { B.S. sieve) should } \\
\text { not exceed } 40 \text { per cent. }\end{array}$ & $\begin{array}{l}\text { The proportion of fines (particles } \\
\text { passing } 0.063 \mathrm{~mm} \text { B.S. sieve) should } \\
\text { not exceed } 20 \text { per cent. }\end{array}$ & $\begin{array}{l}\text { The proportion of fines (particles } \\
\text { passing } 0.063 \mathrm{~mm} \text { B.S. sieve) } \\
\text { should not exceed } 40 \text { per cent. }\end{array}$ \\
\hline $\begin{array}{l}\text { The base of the deposit should lie } \\
\text { within } 25 \text { metres of the surface, this } \\
\text { being taken as the likely maximum } \\
\text { working depth under most } \\
\text { circumstances. } \\
\text { It follows from the second criterion that } \\
\text { boreholes are drilled no deeper than } 18 \\
\text { metres if no sand and gravel has been } \\
\text { proved. }\end{array}$ & $\begin{array}{l}\text { The deposit should lie within } 5 \text { metres } \\
\text { of the surface. }\end{array}$ & $\begin{array}{l}\text { The deposit should lie within } 10 \\
\text { metres of the surface. }\end{array}$ \\
\hline
\end{tabular}

These criteria are far less stringent than those that are used today to delineate a workable deposit (Table 1). Consequently, such thresholds define far greater extents of sand and gravel resources than are likely to be worked within the existing and mid-term economic climate.

Whilst every deposit is unique (and therefore what may be economic to extract in one area may not be in another), consultation with the minerals industry was undertaken to identify a set of generic modern day extraction criteria which can be applied to the original MAR data. From the responses received, two different categories for deposits were identified. A 'Category A' deposit today should average at least 2 metres in thickness and lie within 5 metres of the surface. It should also have an overburden to mineral ratio of $1: 1$ or less and contain less than $20 \%$ fines. Depending on economic viability (specifically location to market) a second category of deposit ('Category B') might be worked today (Table 1). As a result of these criteria changes, any modelling undertaken requires the MAR data to be re-assessed in the context of modern extraction criteria (Table 1), as well as focussing on the distribution of different mineral gradings obtained from within the deposits themselves.

\subsection{D modelling}

Both the MAR maps [26] and the online county mineral resource maps [27] are two dimensional (2D) representations. The purpose of these maps is to show a broad distribution of those mineral resources which may be of current or future economic interest. The extent of mineral resources shown in 2D is generally the inferred surface expression (outcrop) of the resources. However, the true distribution of the resource in 3D may be dipping and thus obscured by different depths of overburden (Figure 1).

\section{[Figure 1 - Outcrop vs. subsurface extent]}

The potential depth to which overburden can be removed in order to extract the mineral resource is dependent on economic and technical factors and will differ between resources and their locations. In addition, sand and gravel deposits are often intercalated with finer grained material that may be deemed as waste, so gaining an understanding of the distribution of different grades of the sand and gravel deposit below ground is vital in estimating its potential to be a mineral reserve.

Whilst access to reliable 2D mineral resource data is proving invaluable in assisting planners, developers and industry in land use planning and decision-making, it does have some limitations. For example, it does not:

(1) Allow for accurate volume estimates of the mineral resource;

(2) Allow for estimates of overburden and intercalation that may affect the resource potential of a deposit;

(3) Easily facilitate the safeguarding of those mineral resources which have a down dip expression and could be economically and technologically extracted, or

(4) Give an indication of quality of sand and gravel (suitability as aggregate) at different depth locations. 
Over the past 20 years, the BGS has progressed from 2D geological mapping to 3D geological modelling and has built up a substantial library of stratigraphic models and surfaces for the UK [23-25, 29-30]. In addition, the BGS has collected associated geological property data to accompany this geological capture (e.g. geotechnical or hydrogeological parameters, such as porosity and permeability) [31]. However, it has only been in recent years that modellers have begun to incorporate this property data into 3D models [7]. This is due to a combination of advances in both software and modelling expertise, along with an increased need to interrogate data in 3D.

\subsection{Uncertainty of geological models}

The 2D and 3D geological models described above can provide planners with useful information about the grade and quantity of mineral deposit that they might expect to find at a particular location. However, these models are formed from relatively sparse observations of the subsurface and are therefore inevitably uncertain. The MAR boreholes were typically separated by more than 1 kilometre. Therefore, to make informed decisions, planners require both a model of the subsurface and an indication of the uncertainty associated with the model. The planners need to know whether the models are sufficiently certain for their purposes or whether further, focussed surveys are required. The geostatistical methodologies presented in this paper are ideally suited to modelling the uncertainty of the subsurface models.

\subsection{Overview of paper}

The main objective of this study was to determine the feasibility of modelling sand and gravel resources, using preexisting data, through the application of modern geostatistical techniques. Specific objectives were to:

(1) Reassess the MAR borehole sand and gravel grading data, taking into account modern extraction criteria and four identified mineral gradings (gravel, coarse sand, fine sand, fines);

(2) Explore and consolidate the most suitable 3D modelling techniques for the sand and gravel gradings to produce a broad-scale understanding of where it is expected that the modern MAR criteria are met and the composition of the deposit;

(3) Use a method that enables assessment of the level of uncertainty within the 3D model;

(4) Produce volume calculations for the four mineral gradings, along with an accompanying assessment of uncertainty, and

(5) Discuss the application of such models to mineral safeguarding and future planning.

This approach has been tested on sand and gravel deposits located around Reading in the south of the UK.

\section{Methodology}

\subsection{Study area}

This study focussed on sand and gravel deposits around Reading, in southern England. The study area was chosen because it has a good spatial coverage of data, with approximately 630 MAR boreholes and over 3000 grain size distributions spread across the mapped mineral deposits (Figure 2). The area also falls within the wider catchment area of the River Thames [32], covering an area of $2400 \mathrm{~km}^{2}$.

The study area lies to the west of London, with the principal urban centres of Reading to the southwest, Maidenhead and High Wycombe to the east and northeast, respectively, and Bracknell to the southeast. The northern and western sectors are mainly rural, with the Chiltern Hills running NE-SW through the northwest corner of the study area.

[Figure 2 - Map of study area]

Mineral resource planning in the study area is divided between five county councils (Buckinghamshire, Hampshire, Hertfordshire, Oxfordshire and Surrey), three London boroughs (Hounslow, Ealing and Hillingdon), and six unitary authorities (Reading, Slough, Bracknell Forest, West Berkshire (Newbury), Windsor \& Maidenhead and Wokingham).

Figure 3 shows the geological succession found at outcrop in the area [33]. Most of the evidence for strata beneath the Chalk group is drawn from deep boreholes.

\section{[Figure 3 - Geological succession]}

The north and north-western parts of the study area are dominated by the Chalk hills of the Chilterns AONB rising to 150 $\mathrm{m}$ above sea level, which are the source of the River Thames [34] and have given rise to deeply incised valleys, covered by thin Quaternary deposits [33]. Softer Palaeogene sediments - mostly clayey layers of the London Clay and Lambeth Group - dominate the central parts of the study area, whilst in the south west and south east are sandier, interfluvial areas comprising the Bracklesham Group and Quaternary sands and gravels [33-35]. 
Quaternary deposits in the region are composed from a combination of river terrace deposits from several ancestral drainage systems (including the Thames, Kennet and Loddon-Blackwater drainage systems), fine-grained flood plain deposits and alluvium, and periglacial mass movement deposits (Figure 2) [33-35]. The sand and gravel deposits are comprised of up to ten levels of river terrace which can be correlated across the entire River Thames catchment [33]. These river terraces have been the subject of several studies over the past few decades as they provide one of the most complete terrestrial records of Pleistocene palaeoclimate reconstructions and climate change in NW Europe [34].

The London and Thames Valley 1:50000 3D geological model [29-30] covers the study area, as well as an adjacent region east towards London. It was constructed using $>7000$ encoded borehole logs in the GSI3D geological modelling environment [36-38]. Lithofacies models and detailed geological descriptions of the Quaternary river terrace deposits along the Thames and the London Basin have been undertaken and published elsewhere [33-40].

\subsection{Data format and pre-processing}

The MAR boreholes were drilled at approximately 1 kilometre intervals and to a maximum depth of 30 metres, although for a variety of reasons, drilling didn't always reach this depth (e.g. drilling was abandoned, the rope broke, the drill head became stuck and could not be retrieved or bedrock was reached). When such technical issues occurred, a second borehole was often sunk close to the original site. The boreholes used in this study had an average depth of 7.5 metres, which has resulted in a large discrepancy between the horizontal (areal) and vertical resolutions (e.g. tens of kilometres horizontally, versus metres vertically).

Each borehole was logged and, where sand and gravel deposits existed, samples were taken at approximately 1 metre intervals down the borehole. Grain size distributions for a range of sieve sizes (64 $\mathrm{mm}$ to $0.063 \mathrm{~mm}$ ) were calculated for each sample. All logs and grading data, along with a range of other index information such as borehole location, start height and depth, borehole content (e.g. mineral, overburden or waste), depth to base and thickness of each graded interval, lithology and stratigraphy are stored in BGS' Sand and Gravel database. Data from all boreholes within the study area were extracted from the database and underwent a series of data pre-processing tasks prior to geostatistical analysis.

Pre-processing tasks included identification of and adjustment for any erroneous or missing data. For example, scientists measuring sieved material either recorded the percentage of material passing through the sieve or the percentage of material retained on the sieve (both using accumulative values). To create a consistent dataset, all measurements were converted to percentage of material retained on the sieve, since this was the most common method of measurement. Another example of erroneous data were inconsistent values, where the percentage of material recorded was less than that retained by the previous sieve, which should not be possible with accumulative measurements. Several samples also had missing data, in that measurements were only taken for every second sieve size. In both situations, the erroneous or missing data were replaced with the percentage from the previous sieve measurement.

\subsubsection{Calculating modern MAR extraction criteria}

In order to calculate the ratio of overburden to mineral (one of the criteria used in the MARs to assess the quality of a deposit), the total thickness of both overburden and mineral needed to be calculated for the top 5 and top 10 metres of each borehole, which are the resource defining depths for Category A and Category B deposits, respectively (Table 1). Likewise, the percentage of fine material in the sand and gravel units lying within 5 and 10 metres of the surface was also calculated.

\subsubsection{Re-categorisation of mineral grades}

Sand and gravel are defined on the basis of particle size rather than composition. One of the limiting factors when using the MAR data to consider aggregate resources in a modern context, is that sediment grain size was categorised to the Wentworth Scale when originally recorded. This defines gravel as over $2 \mathrm{~mm}$. However, in current commercial practice, following the introduction of new European standards from 1st January 2004, the term 'gravel' (or more correctly coarse aggregate) is used for general and concrete applications to define particles between 4 and $80 \mathrm{~mm}$ and the term 'sand' (or fine aggregate) for material that is finer than $4 \mathrm{~mm}$, but coarser than $0.063 \mathrm{~mm}$.

Stakeholder engagement carried out by the BGS has identified that local land-use planning authorities are particularly interested in identifying the location of deposits of coarse sands (particles between $4 \mathrm{~mm}$ and $2 \mathrm{~mm}$ ) which are suitable for use in concrete manufacture. To reflect this in the modelling, the grain size data were re-grouped into the following categories, all of which were modelled in the geostatistical analysis:

$\begin{array}{ll}\text { Gravel: } & >4 \mathrm{~mm}, \\ \text { Coarse sand: } & 4 \mathrm{~mm} \text { to } 2 \mathrm{~mm}, \\ \text { Fine sand: } & <2 \mathrm{~mm} \text { to } 0.063 \mathrm{~mm}, \\ \text { Fines: } & <0.063 \mathrm{~mm} .\end{array}$




\subsection{D grid preparation}

Ideally, the geostatistical analysis would have been conducted within a widely available commercial software package such as GOCAD or Petrel. However, such packages were found to lack the functionality to model the four mineral gradings simultaneously according to the algorithms described in the Appendix. GOCAD was used, however, to produce the $3 \mathrm{D}$ grid through which the geostatistical interpolation would be applied and for both visualisation and volume estimation of the modelled results.

The cleaned data were imported into GOCAD as a series of points in 3D space, each representing the centre point location (XYZ) of each grading analysis. These data points and a digital elevation model (DEM) were used to define the 3D 'volume of interest' (i.e. representing the full 3D extent of the study area). The 'volume of interest' was divided into equally sized grid cells (voxels), each being 1 kilometre by 1 kilometre in area and 1 metre in depth (to reflect the different scales in horizontal and vertical resolution of the dataset) (Figures $4 \mathrm{a}$ and $4 \mathrm{~b}$ ). The uncertainty of a prediction at a site increases according to the distance between that site and an observation. Any grid cell that was further than 3 kilometres from a borehole was removed from the grid (Figure 4c) since examination of the variogram and kriging variances (see Appendix) revealed that the grading predictions at such sites were only marginally more accurate than the mean value of the grading across the study area. Finally, since the modern MAR criteria refer to deposits within 5 and 10 metres of the surface, grid cells below these depths were also removed. This was achieved by projecting the DEM downwards by 5 metres and 10 metres respectively, and using this surface as a cut-off. The final results were two voxel grids, extending down to 5 metres and 10 metres respectively, with equally spaced grid cells no further than 3 kilometres from a borehole.

\section{[Figure 4 - Empty grids]}

Once the 3D grids had been produced, the XYZ coordinates for the centre point of each voxel were exported to csv file so that geostatistical analysis through the grids could be performed outside of GOCAD, within the MATLAB environment. The analyses were performed using a toolbox of geostatistical software developed at BGS. This toolbox has proved reliable for the spatial prediction of environmental data in two and three dimensions (see [41] and references therein) and is available from the authors on request.

\subsection{Geostatistical techniques}

\subsubsection{Overview}

The geostatistical models employed in the study are described in the Appendix. Some of these techniques, such as the use of the linear model of coregionalization to represent the compositional texture gradings, are not included in software packages such as GOCAD [42] and therefore algorithms coded in MATLAB [43] were employed. The aim of the geostatistical modelling exercise was to interpolate the borehole mineral gradings across the 3D grid described above. Samples from the MAR boreholes only had their particle size distribution (grading) assessed if they were from a sand and gravel deposit, therefore, the grading data are not representative of portions of the $3 \mathrm{D}$ grid where waste (e.g. clay) is prevalent (although borehole information about the relative proportions of mineral and waste does exist for these regions). Therefore, two geostatistical models have been estimated in this study. The first one considered the depth of overburden and mineral deposit at each horizontal location in the grid. These modelled properties were then used to decide whether the mineral deposit met the modern MAR criteria in respect of depth to mineral deposit and overburden to mineral ratio (Table 1). The second model considered the MAR grading data. This model was used to predict the proportion of each grading in cells of the 3D grid where the modern MAR criteria (in respect to percent fines content) were satisfied (Table 1). Grading predictions were not calculated in cells where the modern MAR criteria were not satisfied. Leave-one-out cross validation was performed for each of these models to confirm whether the prediction errors were unbiased and the uncertainties of the predictions were accurately quantified.

\subsection{Model 1: modelling the depth of overburden and mineral}

The depths to the base of overburden and mineral deposit were extracted from each borehole. Where no grading was conducted, the material was assumed to be composed entirely of waste. The distributions of both of these properties were highly skewed and therefore a log-transform was applied. The two transformed properties were modelled by a spatial linear model of coregionalization (LMCR). This model describes the spatial correlation for both properties and the spatial cross-correlation between each property. Thus the model accounts for correlation (either positive or negative) between the overburden and mineral depths. The parameters of the model were estimated by maximum likelihood as described in the Appendix. The model was then used to produce 1000 simulations of the two properties at each horizontal grid location using the LU (lower-upper) simulation approach [44]. At each location, the proportion of simulations which satisfied the modern MAR criteria (i.e. the overburden to mineral ratio) was recorded. 


\subsection{Model 2: modelling the mineral gradings}

The grading data (i.e. the proportions of gravel, coarse sand, fine sand and fines) for each borehole were grouped into 1 metre sections. Each one of these sections was treated as an observation. The percentage gradings are compositional properties - they must sum to $100 \%$ in the mineral deposit. This compositional property leads to complex relationships between the different gradings. For example, if the gravel content at a site is $90 \%$ then none of the other components can exceed $10 \%$. Standard geostatistical models for multiple variables might suggest spurious correlations within such data and the resulting predictions or simulations might not sum to $100 \%$.

The additive log ratio transform (Eqn. A8, Appendix) was applied to the data and then an LMCR was estimated for the transformed variables. The distance over which observations of a transformed variable were auto-correlated differed in the vertical and horizontal directions. Therefore, this was accounted for by including geometric anisotropy in the LMCR. This model was rather complex and included 12 parameters. Consequently, the LMCR parameters were estimated by the method of moments estimator [45] rather than the computationally intensive maximum likelihood estimator. One thousand realizations of the transformed properties were produced for each location in the $3 \mathrm{D}$ grid using the estimated LMCR and the LU simulation approach. The simulated values were back-transformed to the original gradings (Eqn. A9, Appendix). Each of the 1000 realizations was paired with a realization of the overburden/mineral depth model (Model 1) described in the previous section. If the modern MAR criteria were not satisfied at the node in the corresponding realization, the gradings were set to zero and the material was assumed to be wholly waste.

\section{$2.7 \quad$ Upscaling}

Each mineral grading applies to a cylinder of material with height 1 metre and cross-sectional area equal to that of the borehole. This cylinder is referred to as the support of the observation. The predictions that are produced by the geostatistical models above are also applicable to volumes of this support. Planners will be interested in the properties of mineral deposits over much larger horizontal areas. Therefore, it was necessary to upscale the predictions.

One approach to upscaling is to produce a set of simulated realizations of the mineral gradings over a very dense 3D grid and then to average these simulated values over larger volumes. The dense grid is required to ensure that the simulations account for the correlations between gradings observed a small distance apart. This approach was unmanageable for the $60 \times 40$ kilometre study area considered here. However, it was possible to produce dense grids over smaller sub-regions, for example, the $0.16 \mathrm{~km}^{2}$ region marked in red on Figure 5. A 3D grid was produced for this region with horizontal spacing of 20 metres and vertical spacing of 1 metre down to 5 metres. One thousand realizations of the two geostatistical models described above were simulated on the nodes of this grid. The proportion of gravel, coarse sand, fine sand, fines and non-mineral material was recorded across all of the nodes for each realization. The proportions for all of the realizations were presented in a box and whisker plot which could be used by a planner to assess the expected proportions in this sub-region and the range of plausible proportions.

[Figure 5 - borehole distribution and focused study area]

\section{Results}

\subsection{Model 1: overburden and mineral depth}

The variograms and cross-variograms for the LMCR of log-transformed overburden and mineral depth are presented in Figure 6 . The continuous lines are the parametric variogram functions estimated by maximum likelihood. The crosses are the point estimates of these variograms for different lag or separation distances which result from the method of moments estimator. The two approaches give consistent results.

\section{[Figure 6 - Variograms]}

The variograms (Figures 6a and 6c) reach their sill variance or maximum value at lag distances of greater than $5 \mathrm{~km}$. This distance is referred to as the range of spatial correlation. Thus, there is a positive correlation between overburden or mineral depths measured in boreholes that are less than 5 kilometres apart. However, the nugget variance (the value at which the variogram crosses the y-axis) is more than half of the sill variance. This indicates that there can be substantial variation in the depths to mineral observed in boreholes that are a very small distance apart. The cross-variogram (Figure $6 \mathrm{~b}$ ) is pure nugget (horizontal) and has a negative nugget variance (i.e. it crosses the y-axis at a negative value). This indicates that there is no spatial correlation between the two depths. The overburden depth recorded at one location is not correlated to the mineral depth recorded in a borehole a small distance away. In addition, there is a negative correlation between the mineral and overburden depths measured in the same borehole. The cross validation results indicate that the model is unbiased. The mean of the observed minus the predicted values is $-0.002 \log (\mathrm{m})$. The accuracy plot shown in Figure $7 \mathrm{a}$ also indicates that the predicted and observed confidence intervals are almost exactly equal.

[Figure 7 - Accuracy plot] 
Distinct areas of deep and shallow overburden (Figure 8a) and mineral deposit (Figure 8b) are evident in the predicted maps of these properties. However, the standard errors (Figures $8 \mathrm{c}$ and $8 \mathrm{~d}$ ) are of a similar magnitude to the predictions. Hence, there are clear underlying spatial trends in the overburden and mineral depths but the values predicted at any specific location are rather uncertain. This reflects the long range of spatial correlation and substantial nugget variance in the variograms described above.

[Figure 8]

Figure 9 shows the probability of the MAR criteria being satisfied across the study region. These probabilities are not calculated for nodes more than 3 kilometres from a borehole. Clear regions are evident where the criteria are more likely or unlikely to be satisfied. However, there is always a substantial component of uncertainty attached to these categorisations.

\section{[Figure 9]}

\subsection{Model 2: mineral gradings}

The variograms and cross-variograms for the mineral gradings have a horizontal range of spatial correlation of up to 17 kilometres (Figure 10) and a vertical range of spatial correlation of more than 2 metres (Figure 11). This horizontal correlation leads to broad-scale patterns in the predicted percentages of all of the gradings (Figure 12) although the percentage of coarse sand and fines are small throughout the study region. Note the proportions in these four maps generally sum to less than $100 \%$ because the percentage of all gradings is zero in cells that fail to satisfy the MAR criteria.

[Figure 10 - Horizontal variograms]

[Figure 11 - Vertical variograms]

[Figure 12 - Grading percentages]

The cross-validation results again indicate that the model is unbiased. The mean difference between the predicted and observed additive log-ratios (see Appendix) was -0.003 . However, there was a slight discrepancy between the predicted and observed confidence intervals (Figure $7 \mathrm{~b}$ ) with, for example, only $85 \%$ of the observed values falling within the $90 \%$ confidence interval. Hence the uncertainty was slightly underestimated by the model. Figure 13 shows a box and whisker plot of the simulated percentages of the four mineral gradings and waste material in the 0.4 kilometre $\times 0.4$ kilometre $\times$ 5 metre subregion illustrated in Figure 5. The solid rectangles in these plots show the interquartile range of these percentages. The horizontal bar within these blocks is the median. The whiskers extend as far as the most extreme percentage that is not considered to be an outlier. The crosses indicate outliers that are more than 2.7 standard deviations from the median.

\section{[Figure 13 - Box and whisker plot]}

The plot illustrates that the coarse sand content of the subregion is almost certain to be less than $8 \%$. The information about the other gradings is less certain reflecting the greater variability of these gradings throughout the study area. Whilst sand and gravel deposits are present in the study area, the modelling undertaken indicates that they comprise gravel and fine sand sized material with little coarse sand (Figure 12).

\subsection{3d visualisation and volume estimates}

Following geostatistical analysis, the predictions for each mineral grading were imported into GOCAD and used to attribute the original 3D grid to enable enhanced visualisation of the results (Figure 14) and to calculate expected volumes of each mineral grading.

[Figure 14 - Results in 3D model]

Expected volumes were calculated by multiplying the average probability of the mineral grade across the area of interest by the volume of the 3D grid, and then adjusting to take into account the presence of waste within the model. The average probability and volume of the 3D grid were calculated from summary statistics within GOCAD, whilst the percentage of the overall study area classed as mineral was determined from the mineral gradings model (Model 2). Table 2 gives the average probability of each mineral grading across the modelled region and the expected volumes in both cubic metres and tonnes. 
Table 2 Expected volumes of each grading across the modelled region

\begin{tabular}{|l|l|l|l|l|}
\hline Grade & $\begin{array}{l}\text { Average } \\
\text { probability } \\
\text { (\% as decimal) }\end{array}$ & $\begin{array}{l}\text { Volume in } \mathbf{~ m}^{\mathbf{3}} \\
\text { (probability } \mathbf{x} \text { grid } \\
\text { volume) }\end{array}$ & $\begin{array}{l}\text { Adjustment for } \\
\text { presence of waste } \\
\mathbf{( x ~ 0 . 0 2 5 2 8 )}\end{array}$ & $\begin{array}{l}\text { Converted to tonnes } \\
\mathbf{( x ~ 1 . 6 4 )}\end{array}$ \\
\hline Coarse sand & 0.0485 & $470,895,736$ & $119,042,442$ & $195,229,605$ \\
\hline Fine sand & 0.3607 & $3,499,286,859$ & $884,619,718$ & $1,450,776,338$ \\
\hline Fines & 0.1809 & $1,754,993,250$ & $443,662,294$ & $727,606,161$ \\
\hline Gravel & 0.4098 & $3,975,299,604$ & $1,004,955,740$ & $1,648,127,413$ \\
\hline
\end{tabular}

\section{Discussion}

National GSOs have a long history of providing mineral resource information and data to aid land-use planning [8-11]. For the BGS, this has traditionally been in the form of 2D MAR maps, grading analyses and online county mineral resource maps [26-27]. Whilst the 2D mineral resource data have proved invaluable to planners and decision makers, there are several limitations, such as not allowing for accurate volume estimations of the resource or an assessment of the overburden or waste intercalations within the deposit. They also do not provide any information about the down-dip expression of deposit, nor do they provide an indication of the suitability of the deposit as aggregate. All of these limitations can be addressed by adopting a 3D modelling approach.

In this study, we have had to consider the limitation in available resources (e.g. modelling software, staff resources and available time), when considering the most appropriate modelling approach. For example, collecting new data - whether by drilling new boreholes or running geophysical surveys - was beyond the remit of this project. A systematic survey and borehole sampling programme of the intensity of that undertaken by the BGS between 1971 and 1990 has never been repeated and is unlikely to be in the foreseeable future. As such, the borehole data and, in particular, the large volume of sand and gravel grading analyses, remain the best dataset available for interpreting the quality of sand and gravel within a potential mineral resource.

The original MAR interpretations for the Reading area [36] comprised 2D surface maps with boreholes used to ascribe large blocks with similar properties. The new method allows a variation of the properties ascribed to blocks with depth, which in turn allows for more detailed models and can represent greater geological complexity. In addition, the original assessment divided the study area into $\sim 2 \mathrm{~km}$ blocks, whereas the method described here allows for much smaller grids. Another advantage of detailed 3D modelling is that it can provide more precise volume calculations and interpretation of the subsurface distribution of a deposit and its properties can be achieved. In addition, these estimates can be differentiated for different mineral gradings, whereas in the original 2D MAR study, volumes were provided for the entire mineral grade, with mean gradings for each modelled block. This type of information is useful to planners when making mineral plans as they are better able to distinguish the composition of sand and gravel deposits e.g. a predominance of fine sand, coarse sand or gravel, and develop policies accordingly.

However, whilst 2D and 3D sand and gravel resource models of the subsurface are useful to land-use planners [8-11], it is vital that they are accompanied by information about their uncertainty. Only then can planners decide whether the model predictions are reliable. One advantage of spatial geostatistical methods, such as the LMCR, over other interpolation methods is that the uncertainty is quantified. The implementation of a geostatistical model, however, requires the user to make assumptions about the spatial variation of the subsurface properties. For example, in this study it was assumed that the same variogram models apply throughout the study region. The estimates of model uncertainty are only reliable when the assumptions are appropriate. The cross-validation of the models indicated that they were both reasonably consistent with the observed data. However, the uncertainty of the mineral grading model was slightly under-estimated. This might reflect the challenges of estimating such a complex spatial model.

Geostatistical model estimators require that the data are not preferentially sampled (i.e. the probability of making an observation at a site is not related to the expected observed value). This was not the case in this study since the grading data were only acquired at sites where mineral deposits were expected. Therefore a second model for the presence or absence of mineral deposits was required. The compositional nature of the data also needed to be accounted for, or else the uncertainty estimates might have been misleading. One word of caution is that the grading data only comes from borehole intervals that are classed as 'mineral', whereas the model predicts for every cell, when some areas will obviously be classed as overburden or waste. Therefore, the gradings model has been censored using the 2D map of overburden and mineral depths simulated in the first model. The reason the model needs censoring in this way is that the model is currently unconstrained by the lithological distribution since this study had been primarily concerned with the mineral gradings data, although lithological constraint will be considered in future work.

The models described here make use of geostatistical methodology to simultaneously interpolate proportions of four mineral grading categories across the study region. The simulations and predictions that result honour the spatial auto- 
and cross-correlation observed between the proportions of the same and different gradings at different locations. Other geological modelling approaches make use of additional data sources or covariates such as seismic refraction tomography data [16-18] to model a variable of interest across a study area. Alternatively modelling approaches can permit the variable of interest to vary according to facies [20] or lithology classes [8]. Our modelling framework can be extended to make use of such additional information in addition to the spatial correlation following an approach [46] that has previously been applied in a $2 \mathrm{D}$ context. The approaches described in this paper contrast with multi-point geostatistics which uses 'training images' (i.e. examples of exhaustive information regarding the variable of interest in a similar context) to build simulations that are consistent with both these training images and the locally observed data [21]. The use of these methodologies to simultaneously represent multiple mineral gradings would represent a substantial theoretical advance.

The principal aim of this research has been to develop a methodology for simulating the quality of sand and gravel resources using stochastic techniques from legacy data. From this, two models have been produced that use borehole data to produce a broad-scale map of the probability that the mineral deposit is viable and to estimate the proportions of different mineral grades. These models have enabled expected volumes of the four mineral gradings to be calculated. Using this approach the uncertainty can be quantified and, although the borehole spacing of approximately one every kilometre may not be suitable for site-specific investigation, it does provide insight into the regional-scale trends that are useful for strategic level planning, both in terms of identifying areas where more detailed investigations might be useful and for safeguarding such areas for the future. This approach to modelling has enabled new analysis of legacy borehole data to provide information on subsurface distribution, quality and volumes of mineral resources and, crucially, provides an assessment of the uncertainty surrounding these predictions. These are a significant addition to the information provided in the existing 2D MARs and county mineral resource maps and could provide important new information to land-use planning authorities who are increasingly interested in these parameters. In addition, the method enables the results to be visualised much more dynamically (i.e. by visualising specific grades or depths) using 3D software, such as GOCAD-SKUA. This is an improvement on the MAR studies which only enabled visualisation of 2D maps with borehole information overlaid and may have been less accessible to those without experience in reading surface geological maps. Perhaps most importantly, is the flexibility of the approach which can be very easily adapted if extraction criteria are changed in future. This has meant that legacy borehole data, which had previously been interpreted in the context of now out-dated extraction criteria, has been re-utilised for modern day requirements.

\section{References}

[1] ONS (2016) UK GDP (O) low level aggregates. Office for National Statistics. https://www.ons.gov.uk/economy/grossdomesticproductgdp/datasets/ukgdpolowlevelaggregates

[2] Wrighton CE, McEvoy EM and Bust R (2011) Mineral safeguarding in England: good practice advice. British Geological Survey, 46pp. Open Report (OR/11/046).

[3] Glacken IM and Snowden DV(2001) Mineral Resource Estimations, in Mineral Resource and Ore Reserve Estimation - The AusIMM Guide to Good Practice (Ed. AC Edwards), pp. 189-198 (The Australian Institute of Mining and Metallurgy, Melbourne).

[4] Rossi ME and Deutsch CV (2014) Mineral resource estimation. Springer Verlag.

[5] Van der Meulen MJ, Doornenbal JC, Gunnink JL, Stafleu J, Schokker J, Vernes RW, van Geer SF, van Heteren S, van Leeuwen RJW, Bakker MAJ, Bogaard PJF, Busschers FS, Griffioen J, Gruijters SHLL, Kiden P, Schroot BM, Simmelink HJ, van Berkel WO, ver der Krogt RAA, Westerhoff WE and van Daalen TM (2013) 3D geology in a 2D country: perspectives for geological surveying in the Netherlands. Geologie en Mijnbouw Netherlands Journal of Geoscience, 92(4):217-241.

[6] Kessler H, Mathers SJ and Sobisch HG (2009) The capture and dissemination of integrated 3D geospatial knowledge at the British Geological Survey using GSI3D software and methodology. Computers and Geosciences 35:1311-1321.

[7] Culshaw MG (2005) From concept towards reality: developing the attributed 3D geological model of the shallow subsurface. Quarterly Journal of Engineering Geology and Hydrogeology. 38:231-284.

[8] Kearsey T, Williams J, Finlayson A, Williamson P, Dobbs M, Marchant B, Kingdon A and Campbell D (2015) Testing the application and limitation of stochastic simulations to predict the lithology of glacial and fluvial deposits in Central Glasgow. Engineering Geology 187:98-112.

[9] Van der Meulen MJ, van Gessel SF and Veldkamp KG (2005) Aggregate resources in the Netherlands. Netherlands Journal of Geosciences - Geologie en Mijnbouw. 84(3):379-387.

[10] Flaherty ST, Malone DH, Thomason JF, Peterson EW and Shields WE (2016) Surficial geology map of the Woodstock, Illinois 7.5 Minute Quadrangle, Mchenry County, Illinois, Scale, 1:24,000. Journal of Maps, 12sup1:387-391. DOI:10.1080/17445647.2016.1227731. 
[11] Pfleiderer S, Untersweg T, Heinrich M and Weber L (2007) The Austrian mineral resources plan - evaluation of aggregates. Geophysical Research Abstracts Volume 9, European Geosciences Union 2007.

[12] Avalos EB, Malone DH, Peterson W, Anderson WP and Gehrels R (2016) Two-Dimensional Seismic Refraction Tomography of a Buried Bedrock Valley at Hallsands Beach, Devon, UK: Environmental Geosciences, v. 23, n. 4, p.179-193. DOI:10.1306/eg.07131615014.

[13] Lau J, Thomason JF, Malone DH and Peterson EW (2016) Modeling the Sediment Fill of the Upper Troy PreGlacial Bedrock Valley, McHenry County, Illinois, USA: Journal of Geoscience and Environment Protection, v. 4, p. 107-122. DOI:10.4236/gep.2016.46010.

[14] Hartz MA, Malone DH, and Nelson RS (2016) Three-Dimensional Modeling of a Glacial Valley Train Outwash Deposit Using Two-Dimensional Seismic Refraction Techniques: Geosciences, v. 6, p. 1-15. DOI:10.3390/geosciences6010009.

[15] Regli C, Huggenberger P and Rauber M (2002) Interpretation of drill core and georader data of coarse gravel deposits. Journal of Hydrology, 255:234-252.

[16] Chambers JE, Wilkinson PB, Weller A, Meldrum PI, Kuras O, Ogilvy RD, Aumonier J, Bailey E, Griffiths N, Matthews B, Penn S and Wardrop D (2012) Characterising sand and gravel deposits using electrical resistivity tomography (ERT): case histories from England and Wales. In: Walton, Geoffrey; Hunger, Emily, (eds.) Proceedings of the 16th Extractive Industry Geology Conference, held at the University of Portsmouth 8th to 11 th September 2010. Extractive Industry Geology Conference, 166-172. http://nora.nerc.ac.uk/id/eprint/20301/1/19 Chambers 166-172_pdf.pdf

[17] Chambers JE, Wilkinson PB, Penn S, Meldrum PI, Kuras O, Loke MH and Gunn DA (2013) River terrace sand and gravel deposit reserve estimation using three-dimensional electrical resistivity tomography for bedrock surface detection. Journal of Applied Geophysics, 93:25-32. https://doi.org/10.1016/j.jappgeo.2013.03.002.

[18] Chambers JE, Wilkinson PB, Wardrop D, Hameed A, Hill I, Jeffrey C, Loke MH, Meldrum PI, Kuras O, Cave $\mathrm{M}$ and Gunn DA (2012) Bedrock detection beneath river terrace deposits using three-dimensional electrical resistivity tomography. Geomorphology, 177-8:17-25. https://doi.org/10.1016/j.geomorph.2012.03.034.

[19] Karaka ŞA (2014) Defining the suitability of new crushed rock aggregate source areas in the North of Kocaeli Province using GIS. Bulletin of Engineering Geology and the Environment. 73(4):1183-1197.

[20] Falivene O, Cabrera L, Muñoz JA, Arbués P, Fernández O and Sáez A (2007) Statistical grid-based facies reconstruction and modelling for sedimentary bodies. Alluvial-palustrine and turbiditic examples. Geologica Acta, 5(3):199-230.

[21] Comunian A, Renard P, Straubhaar J and Bayer P (2011) Three-dimensional high resolution fluvio-glacial aquifer analog - Part 2: Geostatistical modelling. Journal of Hydrology, 405:10-23. doi:10.1016/j.jhydrol.2011.03.037.

[22] Williams JDO, Dobbs MR, Kingdon A, Lark RM, Williamson JP, MacDonald AM and Ó Dochartaigh BÉ (in press) Stochastic modelling of hydraulic conductivity derived from geotechnical data: an example applied to Central Glasgow. Earth and Environmental Science Transactions of the Royal Society of Edinburgh.

[23] Jones LD and Terrington R (2011) Modelling volume change potential in the London clay. Quarterly Journal of Engineering Geology and Hydrogeology, 44 (1):109-122. 10.1144/1470-9236/08-112.

[24] Kessler, H., Mathers, S.J., Sobisch, H-G., 2009. The capture and dissemination of integrated 3D geospatial knowledge at the British Geological Survey using GSI3D software and methodology. Comput. Geosci. 35, 1311-1321.

[25] Kessler, H., Mathers, S.J., 2004. From geological maps to models - finally capturing the geologists' vision. Geoscientist 14/10, 4-6.

[26] British Geological Survey. Mineral Assessment Reports. Industrial Minerals Assessment Unit. http://www.bgs.ac.uk/mineralsuk/mines/IMAU.html

[27] British Geological Survey. Mineral Resource Maps for the UK by planning area. http://www.bgs.ac.uk/mineralsuk/planning/resource.html

[28] PERC (2013) Pan European standard for reporting of exploration results, mineral resources and reserves. The Pan European reserves and resources reporting committee, revision 2:29 November 2013.

[29] Waters CN, Terrington RL, Cooper MR, Raine RJ and Thorpe S (2016) The construction of a bedrock geology model for the UK: UK3D_v2015. British Geological Survey, 22pp. Open Report (OR/15/069) (http://nora.nerc.ac.uk/512904/). 
[30] Mathers SJ and Kessler H (2010) Shallow sub-surface 3D geological models for Earth \& Environmental Science decision making. Environmental Earth Science 60(2):445-448.

[31] Kingdon A, Nayembil ML, Richardson AE Smith AG (2016) A geodata warehouse: using denormalisation techniques as a tool for delivering spatially enabled integrated geological information to geologists. Computers and Geosciences, 96:87-97.10.1016/j.cageo.2016.07.016.

[32] Environment Agency (2009) River basin management plan - Thames river basin district. Publication 651 Environment Agency: Bristol, pp. 89.

[33] Mathers SJ and Smith NJP (2000) Geology of the Reading District - a brief explanation of the geological map. Sheet Explanation of the British Geological Survey. 1:50 000 Sheet 268 Reading (England and Wales).

[34] Royse KR, de Freitas M, Burgess WG, Cosgrove J, Ghail RC, Gibbard P, King, C, Lawrence U, Mortimore RN, Owen H and Skipper J (2012) Geology of London, UK. Proceedings of the Geologists' Association, 123(1):2245. doi.org/10.1016/j.pgeola.2011.07.005.

[35] Maddy D, Bridgland D and Westway R (2001) Uplift-driven valley incision and climate-controlled river terrace development in the Thames Valley, UK. Quaternary International, 79:23-36.

[36] Squirrell HC (1978) The sand and gravel resources of the country around Sonning and Henley, Berkshire, Oxfordshire and Buckinghamshire: Description of 1:25000 resource sheets SU77 and SU78. Mineral Assessment Reports No. 32.

[37] Mathers SJ, Burke HF, Terrington RL, Thorpe S, Dearden RA, Williamson JP and Ford JR (2014) A geological model of London and the Thames Valley, southeast England. Proceedings of the Geologists' Association, 125:373-382. http://dx.doi.org/10.1016/j.pgeola.2014.09.001.

[38] Burke H, Mathers S, Williamson JP, Thorpe S, Ford J and Terrington R (2014) The London Basin superficial and bedrock LithoFrame 50 model. British Geological Survey Open Report, OR/14/029, 31 pp.

[39] Gibbard PL (1994) Pleistocene history of the Lower Thames valley, Cambridge University Press.

[40] Gibbard PL, Whiteman CA and Bridgland DR (1988) A preliminary report on the stratigraphy of the Lower Thames valley. Quaternary Newsletter, 56:1-8.

[41] Marchant BP (2018) Model-based geostatistics. In: McBratney, A.B., Minasny, B., Stockmann, U. (eds), Pedometrics: A system of quantitative soil information. Springer.

[42] Mallet, JL (1992) GOCAD: A computer aided design program for geological applications. In: A.K. Turner (Ed.) Three-dimensional modelling with geoscientific information systems, NATO ASI Series, Volume, 354, pp 123141, Springer, Netherlands.

[43] Mathworks (2014) MATLAB and Statistics Toolbox Release 2014b, The MathWorks, Inc., Natick, Massachusetts, United States.

[44] Deutsch CV and Journel AG (1998) GSLIB: geostatistical software library and user's guide. Second Edition, pp. 369. Oxford University Press, Oxford, New York.

[45] Webster R and Oliver MA (2007) Geostatistics for Environmental Scientists: Second edition. Wiley, Chichester, UK.

[46] Lark RM, Marchant BP, Dove D, Green SL, Stewart H and Diesing M (2015) Combining observations with swath bathymetry and backscatter to map seabed sediment texture classes; the empirical best linear unbiased predictor. Sedimentary Geology, 328: 17-32.

[47] Marchant BP and Lark RM (2007a) The Matérn variogram model: Implications for uncertainty propagation and sampling in geostatistical surveys. Geoderma, 140(4):337-345.

[48] Marchant BP and Lark RM (2007b) Estimation of linear models of coregionalization by residual maximum likelihood. European Journal of Soil Science, 58(6):1506-1513.

[49] Goovaerts P (2001) Geostatistical modelling of uncertainty in soil science. Geoderma, 103:3-26. 


\section{Appendix}

\section{Statistical Background}

Geostatistical models are commonly used in the mining industry to interpolate two- or three-dimensional predictions of a deposit and to quantify the uncertainty of these predictions. Standard geostatistical models can be estimated and manipulated within software packages such as GOCAD [42]. This appendix summarises the statistical theory required to understand our modelling methodology. Fuller theoretical descriptions of all of these methods with the exception of the techniques for compositional data can be found in accessible textbooks such as [45]. The technical aspects of the spatial prediction of compositional properties are described by [46]

\section{Geostatistical modelling in two dimensions}

Environmental properties are often spatially correlated. This means that observations of such properties made a short distance apart are more likely to be similar than disparate observations. Geostatistical methods quantify and use this spatial correlation to predict the value of the property at a location where it has not been observed and to calculate the uncertainty of this prediction.

The spatial correlation of a property, $z$, is generally expressed in terms of its variogram:

$$
\gamma(\mathbf{h})=\frac{1}{2} E\left[\{z(\mathbf{x})-z(\mathbf{x}+\mathbf{h})\}^{2}\right]
$$

Here, $\mathbf{x}$, is a location at which the property is observed, $\mathbf{h}$ is a lag vector and $E[. .$.$] denotes the expected value of the term$ in brackets. The variogram describes how the expected squared difference between a pair of observations varies as the vector separating them is changed. The variogram might vary according to both the direction and magnitude of $\mathbf{h}$. Such a variogram is said to be anisotropic. If the variogram is isotropic then the $\mathbf{h}$ in Eqn. A1 is replaced by the magnitude of the lag vector which we denote $h$.

The variogram must be estimated from observations of the property of interest. This is often achieved by the method of moments [45]. Here, point estimates of the variogram are estimated for different lag distances:

$$
\hat{\gamma}\left(h_{i}\right)=\frac{1}{2 m\left(h_{i}\right)} \sum_{j=1}^{m\left(h_{i}\right)}\left\{z\left(\mathbf{x}_{j, 1}\right)-z\left(\mathbf{x}_{j, 2}\right)\right\}^{2} .
$$

This point estimator applies to the isotropic case, $\mathbf{x}_{j, 1}$ and $\mathbf{x}_{j, 2}$ denote a pair of observation locations approximately separated by lag distance $h_{i}$ and $m\left(h_{i}\right)$ denotes the total number of such pairs of points. Then a parametric function is fitted to these point estimates by a least squares approach. Several suitable parametric functions exist. The highly flexible Matérn function is often advocated [47]. This function has four parameters: a nugget, $c_{0}$, which is the variance of the spatially uncorrelated component of the property; a sill, $c_{1}$, which is the variance of the spatially correlated component, a spatial parameter, $a$, which reflects the distance over which the property is spatially correlated and a smoothness parameter, $v$, which describes the shape of the variogram. One disadvantage of the method of moments approach is that the fitted model can be influenced by the seemingly arbitrary selections of the set of lag distances at which point estimates are calculated and the tolerance on pairs of points which are considered to be approximately separated by these distances. Also, the method of moments approach does not account for correlations between the point estimates for different lag vectors. These issues do not arise if the variogram is estimated by maximum likelihood [48].

If the observed property is assumed to be a Gaussian random variable then it is possible to calculate the likelihood that the observed values would have arisen from a random function with a proposed set of variogram parameters. The maximum likelihood estimator uses a numerical algorithm to find the parameter values that lead to the largest likelihood value. The maximum likelihood approach is considered to have statistical rigour but for complex spatial models it is a numerical challenge to find the parameter values which lead to the largest likelihood. If the assumption of a Gaussian variable is inappropriate, then a transformation can be applied to the observed data. 
Once a parametric estimate of the variogram is available, the value of a property can be predicted at a site where it has not been observed by kriging. The kriged prediction is a weighted sum of the values of the property observed nearby. The weights decrease as the distance between the observed value and the prediction site increases in a manner that is related to the fitted variogram function. The kriging approach also calculates the variance or uncertainty of the prediction.

It is also possible to use the fitted variogram to simulate realizations of a spatially correlated property at each node of a grid. Each realization will contain realistic patterns of variation and the differences between the realizations will reflect the uncertainty of the predictions at each grid point. Several geostatistical simulation algorithms exist [44] but we favour the lower-upper (LU) approach which can quickly produce a large number of realizations. The primary drawback of this approach is that a set of realizations on a grid with $n$ nodes, requires the Cholesky decomposition of a $n \times n$ matrix. This is a relatively computationally intensive matrix operation which is impractical, on a 32 GB RAM computer running Matlab, for $n>15,000$.

\section{Geostatistical modelling in three dimensions}

Environmental properties observed at a single depth are often assumed to have an isotropic variogram. This assumption is rarely appropriate if the property is observed at different depths because the pattern of vertical variation is very different to the lateral variation. Therefore, three dimensional models often require an anisotropic variogram. A geometric anisotropic model permits the range of the variogram to be stretched or contracted in a particular direction. For example, we might replace the lag vector in Eqn. A1 with

$$
h=\sqrt{h_{x}^{2}+h_{y}^{2}+\alpha h_{z}^{2}}
$$

Here, $h_{x}$ and $h_{y}$ are the distances separating a pair of points in the two lateral directions, $h_{z}$ is the vertical separation and $\alpha>0$ is a model parameter. When $\alpha=1$, the model is isotropic. Other values of $\alpha$ lead to the vertical range being stretched or contracted in relation to the horizontal range. Such a variogram model can be estimated using either the method of moments or the maximum likelihood estimators. The method of moments approach requires separate point estimates of the variogram to be produced for pairs of points that are separated vertically, horizontally or in both directions.

\section{Geostatistical models of multiple properties}

If geostatistical models of multiple properties are required then the spatial correlation between these properties must be quantified. This can be achieved by estimating a linear model of coregionalization (LMCR). Consider two spatial properties which we denote $z_{u}(\mathbf{x})$ and $z_{v}(\mathbf{x})$. The LMCR for these properties consists of a variogram of $z_{u}(\mathbf{x})$ (which we denote $\left.\gamma^{u, u}\right)$, a variogram of $z_{v}(\mathbf{x})$ (denoted $\gamma^{v, v}$ ) and a cross-variogram between $z_{u}(\mathbf{x})$ and $z_{v}(\mathbf{x})$ :

$$
\gamma^{u, v}(\mathbf{h})=\frac{1}{2} \mathrm{E}\left[\left\{z_{u}(\mathbf{x})-z_{u}(\mathbf{x}+\mathbf{h})\right\}\left\{z_{v}(\mathbf{x})-z_{v}(\mathbf{x}+\mathbf{h})\right\}\right]
$$

Parametric models for each variogram and cross-variogram can again be estimated by both the method of moments and maximum likelihood estimators [48]. In the case of the method of moments, the point estimates of the cross-variogram are [45]:

$$
\hat{\gamma}^{u, v}\left(\mathbf{h}_{i}\right)=\frac{1}{2 m\left(\mathbf{h}_{i}\right)} \sum_{j=1}^{m\left(\mathbf{h}_{i}\right)}\left\{z_{u}\left(\mathbf{x}_{j, 1}\right)-z_{u}\left(\mathbf{x}_{j, 2}\right)\right\}\left\{z_{v}\left(\mathbf{x}_{j, 1}\right)-z_{v}\left(\mathbf{x}_{j, 2}\right)\right\}
$$

For the LMCR to be valid, all of the variograms and cross-variograms must have the same range and smoothness parameter and:

$$
\left|c_{0}^{u, v}\right|<\sqrt{c_{0}^{u} c_{0}^{v}} \quad \text { and }\left|c_{1}^{u, v}\right|<\sqrt{c_{1}^{u} c_{1}^{v}}
$$


where $c_{0}^{u, v}$ and $c_{1}^{u, v}$ denote the nugget and sill parameters of the cross-variogram model and $c_{0}^{u}$ and $c_{1}^{u}$ are the nugget and sill of $z_{u}(\mathbf{x})$. The LMCR can be extended to more than two properties. In this situation, a variogram is required for each property and a cross-variogram for each pair of properties. The constraint on the nugget and sill parameters requires that the determinants of the matrices of all of these parameters are strictly positive:

$$
\left(\begin{array}{ccc}
c_{0}^{u} & c_{0}^{u, v} & \ldots \\
c_{0}^{u, v} & c_{0}^{v} & \ldots \\
\vdots & \vdots & \ddots
\end{array}\right) \text { and }\left(\begin{array}{ccc}
c_{1}^{u} & c_{1}^{u, v} & \ldots \\
c_{1}^{u, v} & c_{1}^{v} & \ldots \\
\vdots & \vdots & \ddots
\end{array}\right)
$$

An estimated LMCR can be used to krige and simulate multiple spatial properties in the same manner as the univariate case.

\section{Geostatistical models of compositional properties}

Compositional properties are those which have a known sum. For example in the mineral deposits considered in this paper, the percentages of gravels, coarse sands, fine sands and fines at a specified location must sum to 100. Therefore, if we know the percentage of three of the gradings then we can determine the fourth. If we were to include each of the four gradings, $g_{i} i=1, \ldots 4$, in an LMCR then the resulting predictions and simulations will not necessarily sum to 100 . Instead, the additive log ratio transform:

$$
z_{1}=\log \left(\frac{g_{1}}{g_{4}}\right) ; z_{2}=\log \left(\frac{g_{2}}{g_{4}}\right) ; z_{3}=\log \left(\frac{g_{3}}{g_{4}}\right)
$$

might be performed [46]. It is not important which of the gradings is selected as the denominator of the ratios in Eqn. A8 although if that grading is ever zero then a small positive shift should be added to it. These three transformed properties can then be represented by an LMCR and predictions and simulations of them can be produced. Each set of simulated values must be back-transformed to the original gradings by:

$$
\begin{gathered}
g_{i}=\frac{100 \exp \left(z_{i}\right)}{1+\exp \left(z_{1}\right)+\exp \left(z_{2}\right)+\exp \left(z_{3}\right)} \text { for } i=1,2,3 \\
g_{4}=\frac{100}{1+\exp \left(z_{1}\right)+\exp \left(z_{2}\right)+\exp \left(z_{3}\right)},
\end{gathered}
$$

and any shift in $g_{4}$ should be subtracted. This approach ensures that the simulated gradings at each site sum to $100 \%$ and that these simulated values honour the spatial and between-grading correlations observed in the borehole data.

\section{Validation of geostatistical models}

It is important to confirm that the predictions from geostatistical models are consistent with the observed data. Discrepancies between observed and predicted values can occur if the models are based on inappropriate assumptions or if the model estimation procedure does not work correctly. Ideally, a substantial proportion of would be held-back from the model calibration procedure for such validation of the model. More generally, a cross-validation procedure is employed where a small number of observations are held-back and the remainder are used to predict the property of interest at the locations of the held-back data. Then the process is repeated, holding back a different set of observations each time, until cross-validation has been performed at a substantial number of locations. Quantities such as the mean of the predicted value minus the observed value can be used to confirm there is no bias in the predictions. It is also possible to test whether the uncertainty in the predictions has been appropriately modelled. This is achieved by calculating the 
standardised squared prediction error (SSPE) for each cross-validation site. This quantity is defined as the squared difference between the observed and predicted values all divided by the prediction variance. If the model errors are realized from a Normal distribution then the SSPE should be distributed according to a chi-squared distribution and hence it is possible to determine the probability (according to the geostatistical model) that such an error as extreme as this will have occurred. These probabilities might then be presented in an accuracy plot [49] which shows the proportion of crossvalidation predictions that fall within any specified confidence interval. 


\section{Figures}

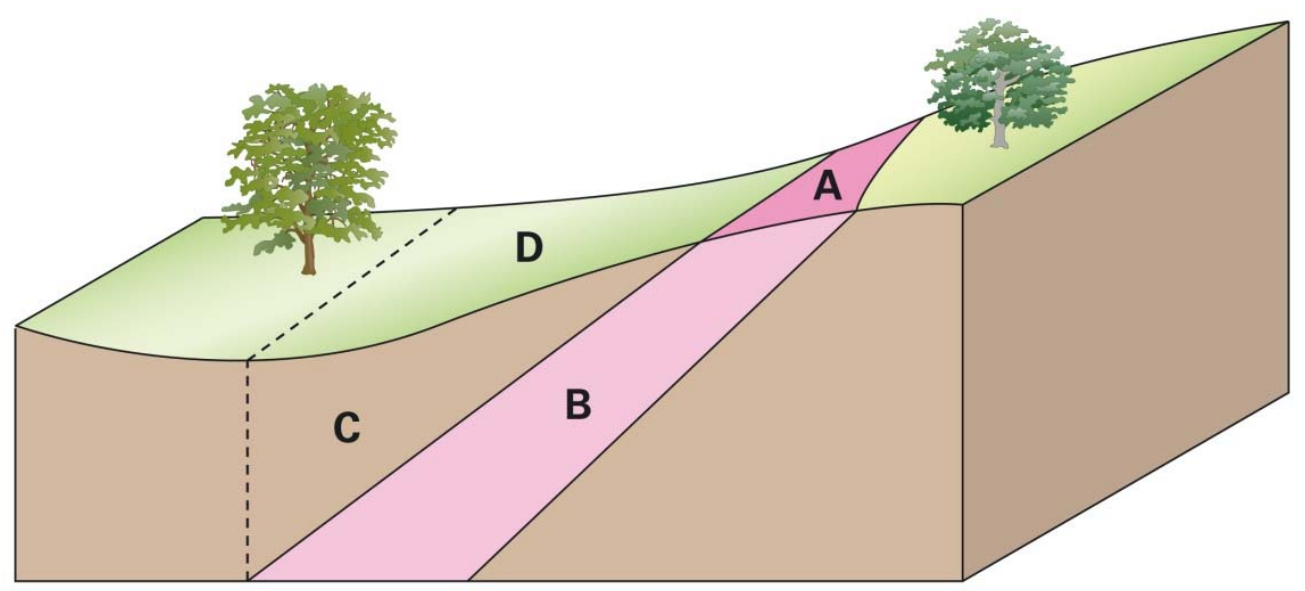

Fig. 1 Difference between (A) surface expression (outcrop) and (B) possible subsurface extent of geological formation. (C) Shows where overburden is adjacent to the outcrop area and may conceal the full extent of the formation when viewed in $2 \mathrm{D}$ plan and (D) shows the area of land needing to be safeguarded for potential future extraction. 

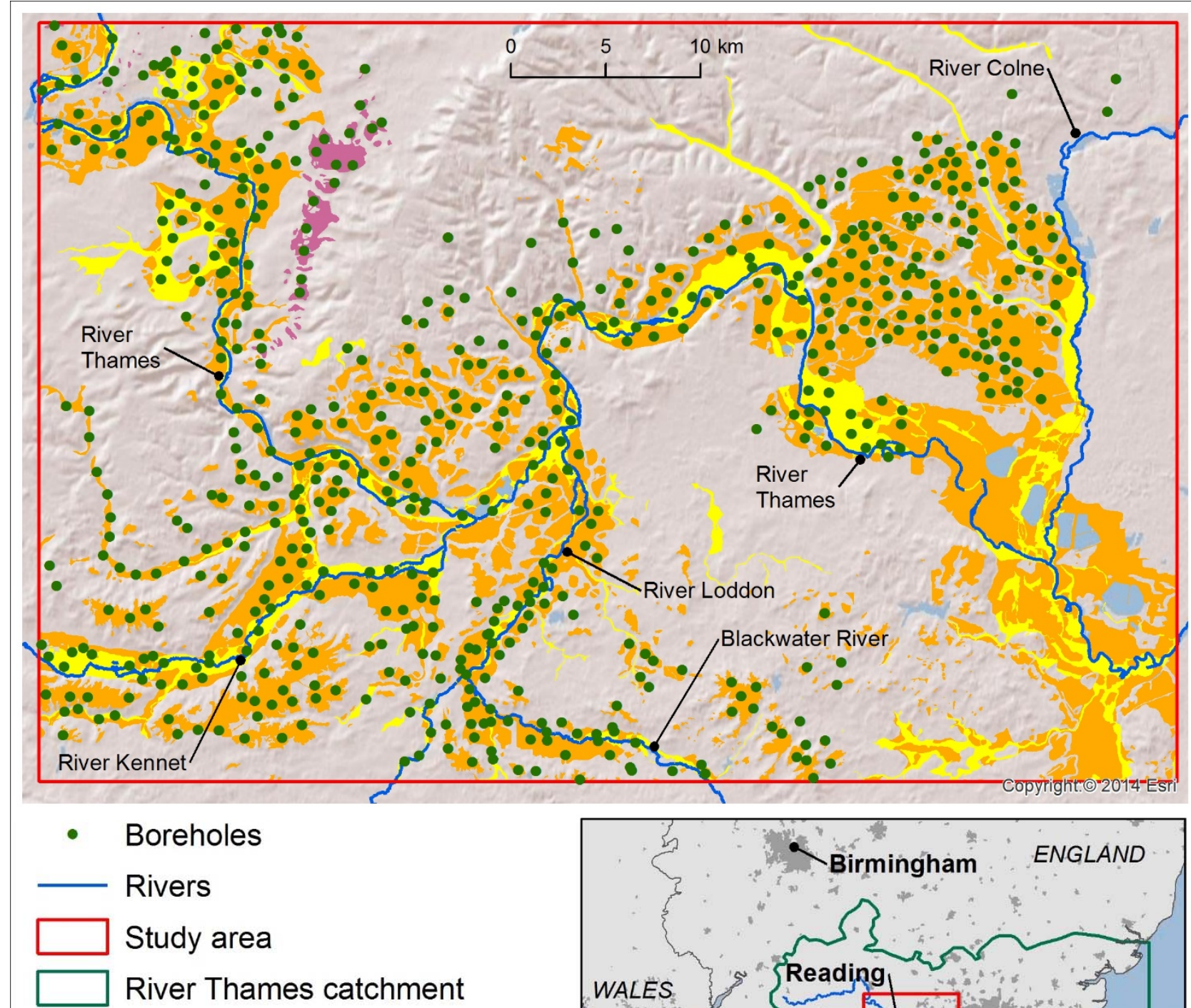

\section{Sand and gravel deposits}
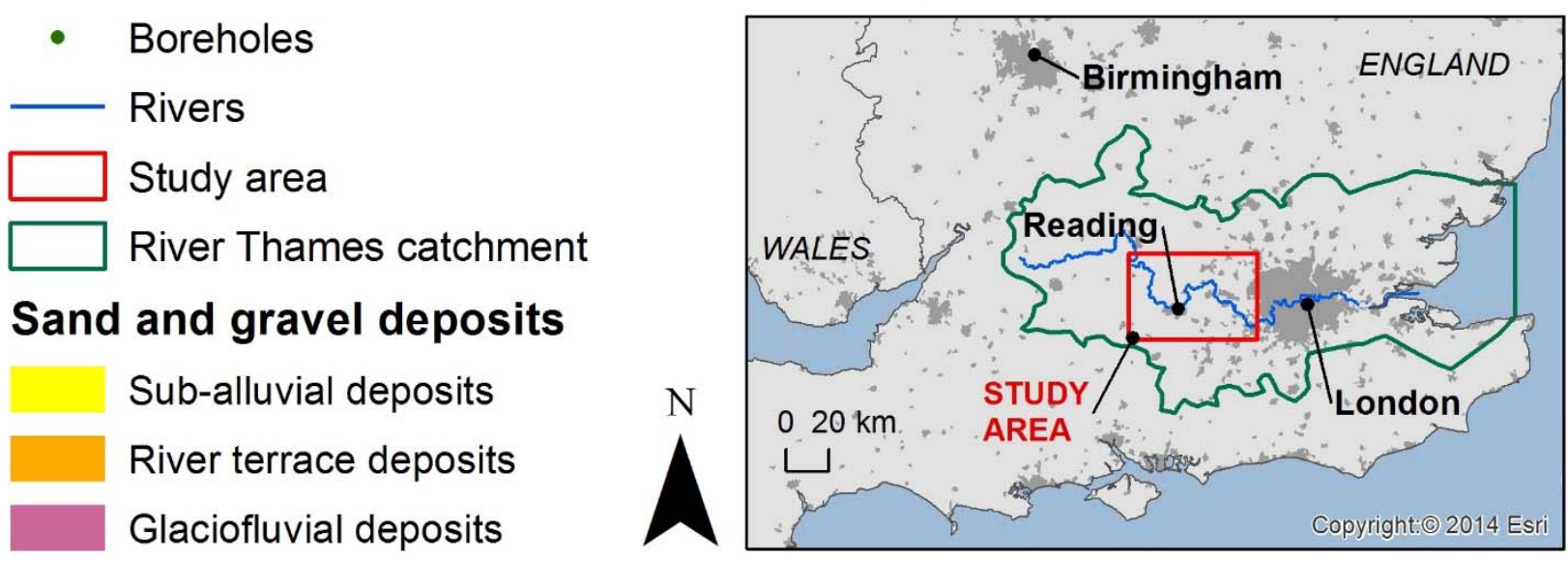

Fig. 2 Map of study area to the west of Greater London, showing distribution of boreholes used in the model, and distribution of mapped sand and gravel deposits (based on [8]). [Map sources: World Shaded Relief base map (C) ESRI 2014. National boundaries, urban areas and rivers, Ordnance Survey data (C) Crown Copyright and database rights 2018. Ordnance Survey Licence No. 100021290 EUL. Figure created using ArcGIS. Copyright (C) Esri. All rights reserved]. 


\begin{tabular}{|c|c|c|c|}
\hline AGE & \multicolumn{3}{|c|}{ GROUP / FORMATION / LITHOLOGY } \\
\hline \multirow{2}{*}{ 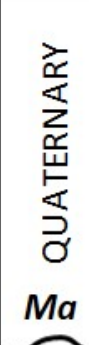 } & \multicolumn{2}{|c|}{ Artificial (man-made) deposits } & \multirow[b]{2}{*}{$\begin{array}{l}\text { Mass-movement deposits: } \\
\text { Head } \\
\text { Head gravel } \\
\text { Clay-with-flints }\end{array}$} \\
\hline & \multicolumn{2}{|c|}{$\begin{array}{l}\text { Alluvium } \\
\text { Brickearth } \\
\text { Langley Silt } \\
\text { River Terrace Deposits }\end{array}$} & \\
\hline \multirow{5}{*}{ 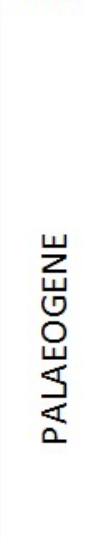 } & \multirow{3}{*}{$\begin{array}{l}\text { Brackle- } \\
\text { sham } \\
\text { Group }\end{array}$} & $\begin{array}{l}\text { Camberley Sand } \\
\text { Formation }\end{array}$ & $\begin{array}{l}\text { Fine-grained sand with thin } \\
\text { clay lenses }\end{array}$ \\
\hline & & $\begin{array}{l}\text { Windlesham } \\
\text { Formation }\end{array}$ & Sand and clay \\
\hline & & Bagshot Formation & $\begin{array}{l}\text { Fine- to medium-grained } \\
\text { sand, silt and clay layers }\end{array}$ \\
\hline & \multirow[t]{2}{*}{$\begin{array}{l}\text { Thames } \\
\text { Group }\end{array}$} & $\begin{array}{l}\text { London Clay } \\
\text { Formation }\end{array}$ & $\begin{array}{l}\text { Clay and silty clay; } \\
\text { subordinate sands, silts and } \\
\text { flint pebbles }\end{array}$ \\
\hline & & Harwich Formation & Sand and clay \\
\hline 54.8 & $\begin{array}{l}\text { Lambeth } \\
\text { Group }\end{array}$ & Reading Formation & Clay with sand beds \\
\hline \multirow{3}{*}{ 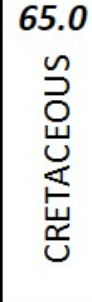 } & \multirow{3}{*}{$\begin{array}{l}\text { Chalk } \\
\text { Group }\end{array}$} & Upnor Formation & $\begin{array}{l}\text { White nodular chalk with } \\
\text { flints }\end{array}$ \\
\hline & & Middle Chalk & $\begin{array}{l}\text { White, soft and nodular } \\
\text { chalk }\end{array}$ \\
\hline & & Lower Chalk & Gray marly chalk \\
\hline
\end{tabular}

Fig. 3 Geological succession in the Reading district, adapted from [8]. 

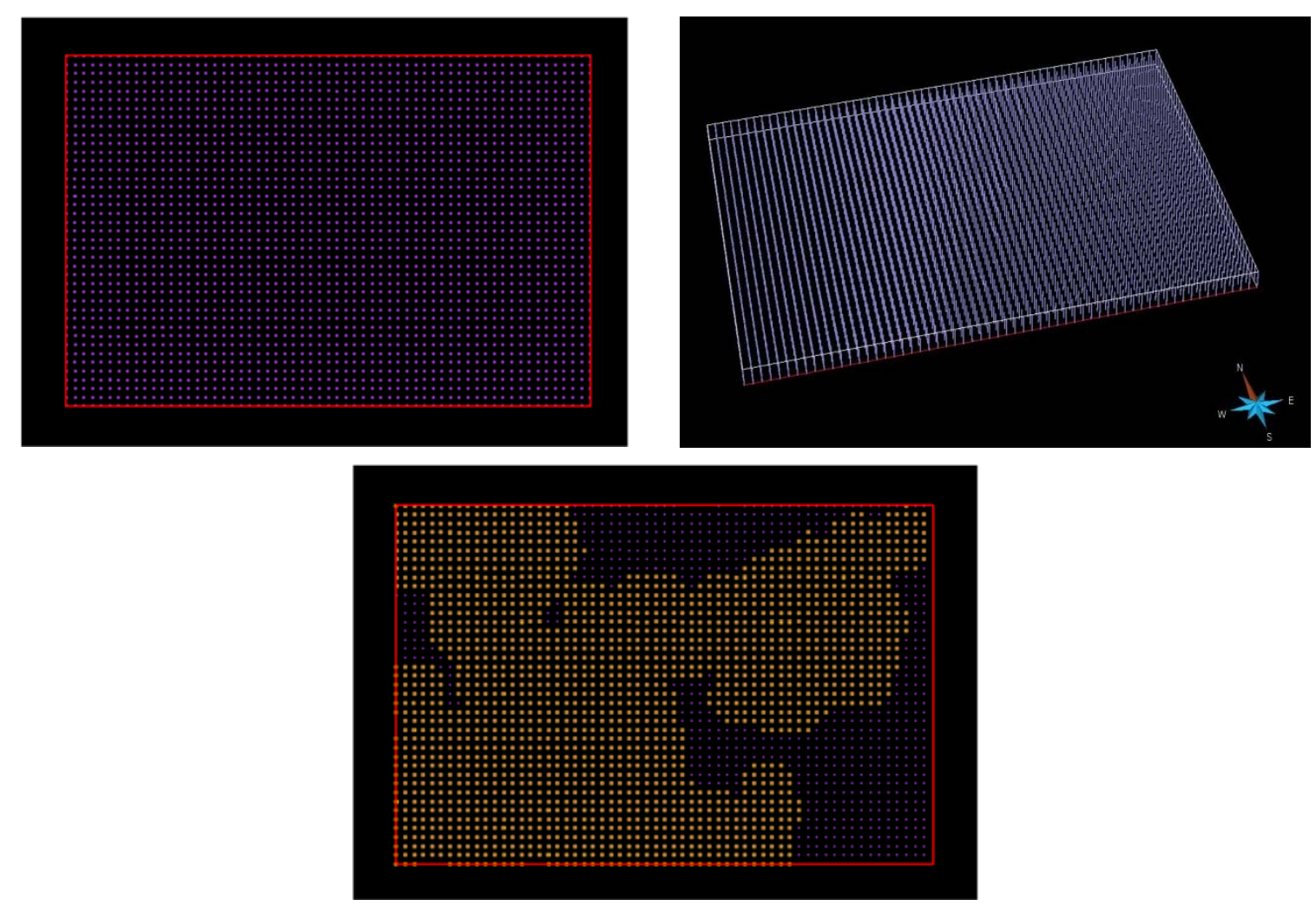

Fig. 4 3D grid creation for geostatistical analysis, showing: (a) centre point of each grid cell in 2D view; (b) grid in 3D view (x 10 vertical exaggeration), and; (3) final grid with cells $>3$ kilometres from a borehole removed. Grids built in GOCAD $^{\mathrm{TM}}$. 


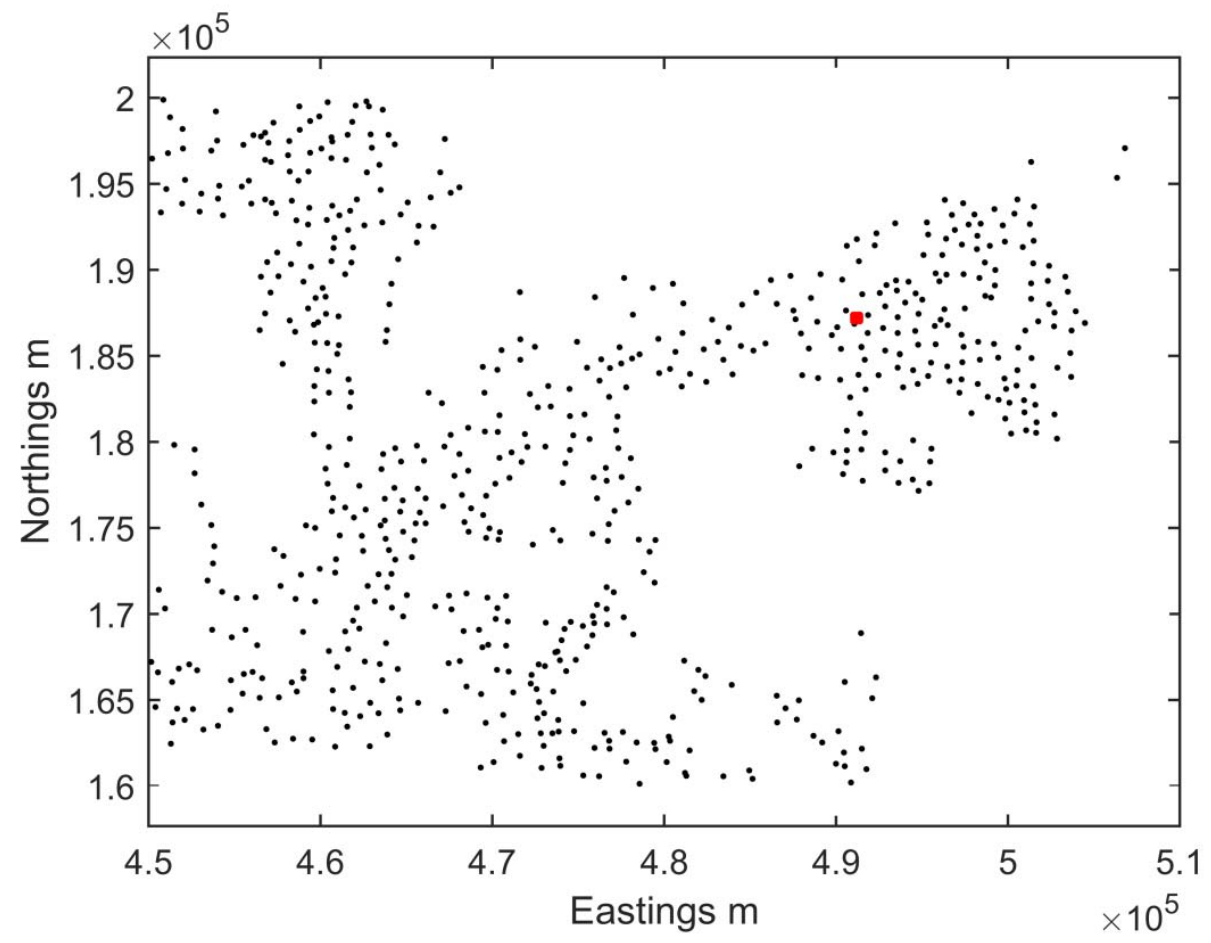

Fig. 5 Locations of IMAU boreholes (black dots). Red dot indicates the location of the box-whisker plot of uncertainty shown in Figure 13. 

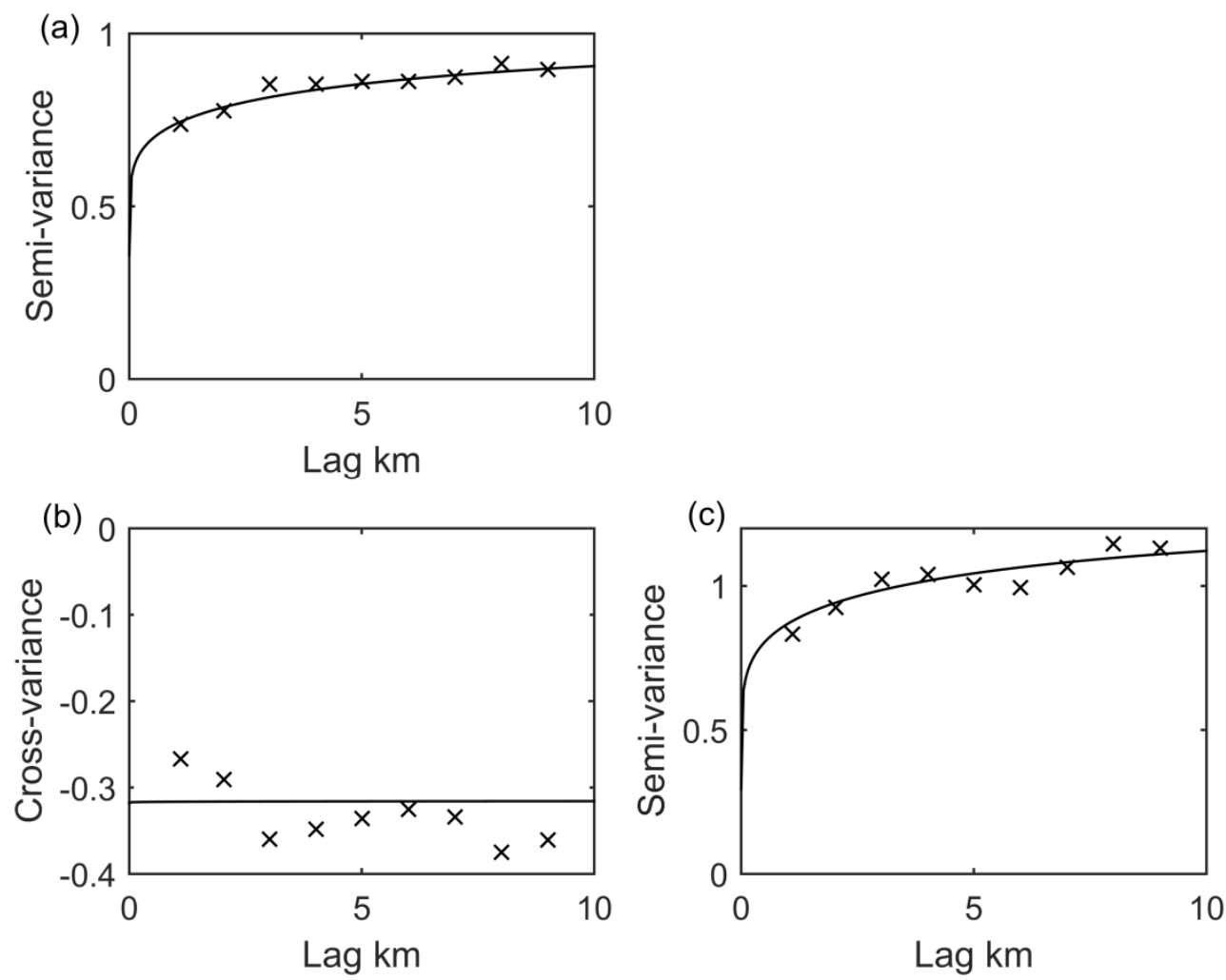

Fig. 6 (a) Estimated variogram for log overburden depth, (b) estimated cross-variogram for log overburden depth and log mineral deposit depth, (c) estimated variogram for log mineral deposit depth. Point estimates are denoted by crosses and maximum likelihood estimates by continuous curves. Units of variances are $(\log (\mathrm{m}))^{2}$. 

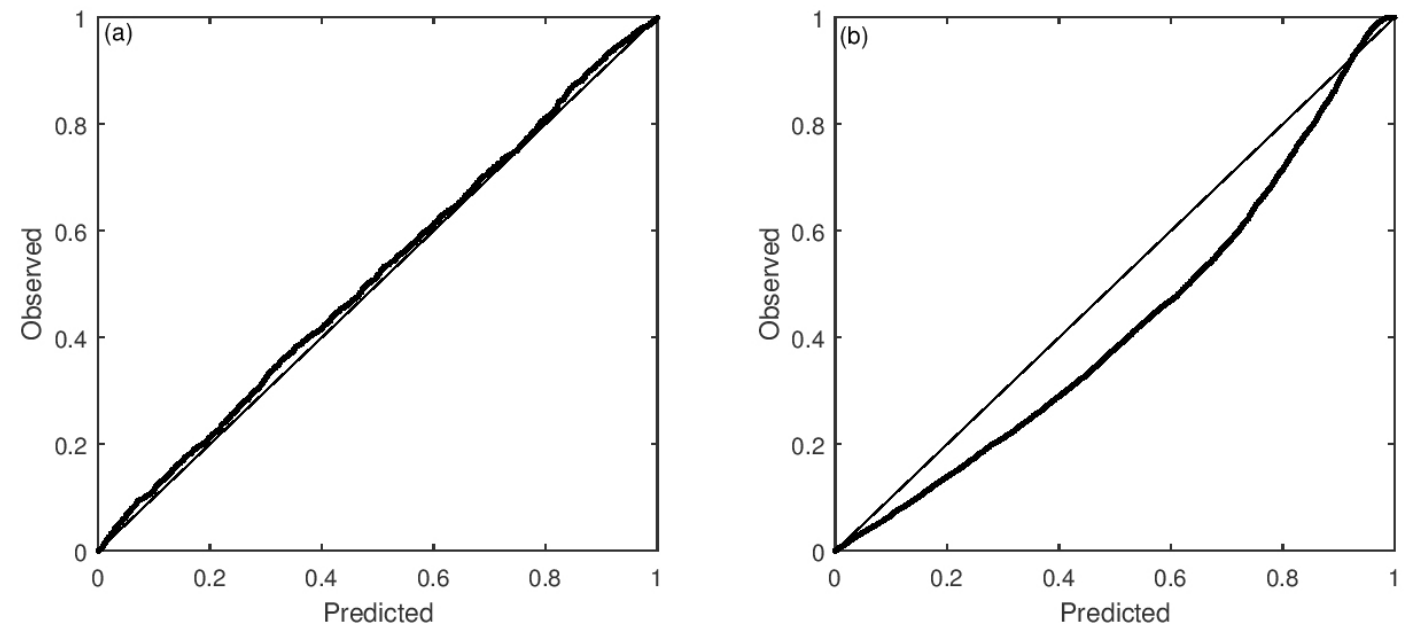

Fig. 7 Plot of predicted and observed proportions of observations falling into different confidence intervals upon leaveone-out cross-validation for (a) the overburden and mineral depth model and (b) the mineral grading model. 
(a)

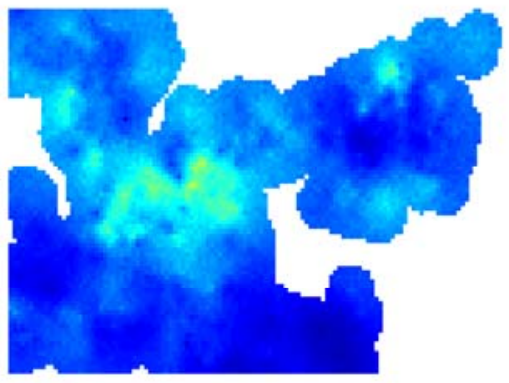

(c)

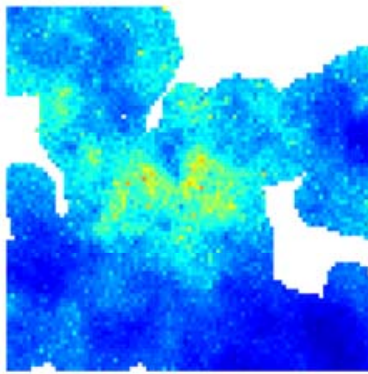

(b)

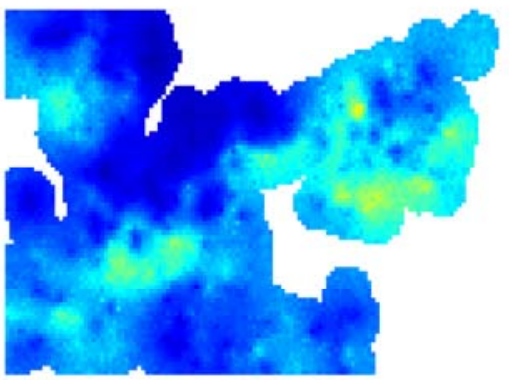

(d)

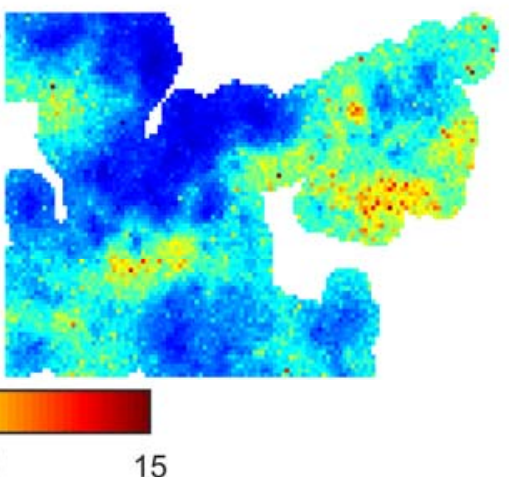

Fig. 8 (a) Estimated depth, metres, of overburden, (b) estimated depth, metres, of mineral deposit, (c) standard error, metres, of overburden depth estimate, (d) standard error, metres, of mineral deposit depth estimate. 
To $5 \mathrm{~m}$; overburden:mineral<1:1

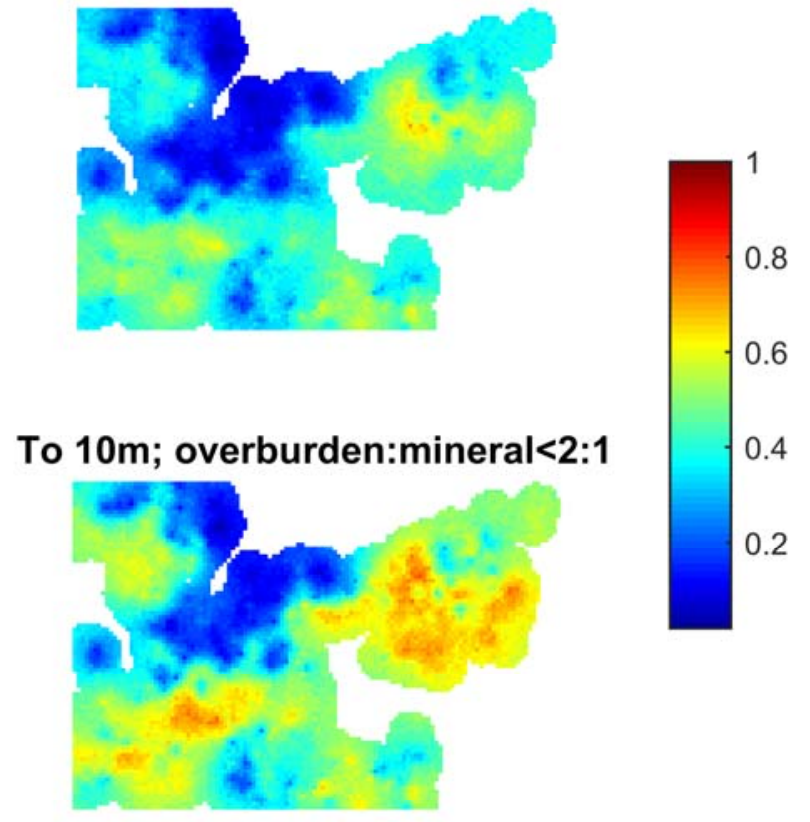

Fig. 9 Probability of satisfying MAR criteria to a depth of $5 \mathrm{~m}$ (a) and a depth of $10 \mathrm{~m}$ (b). 

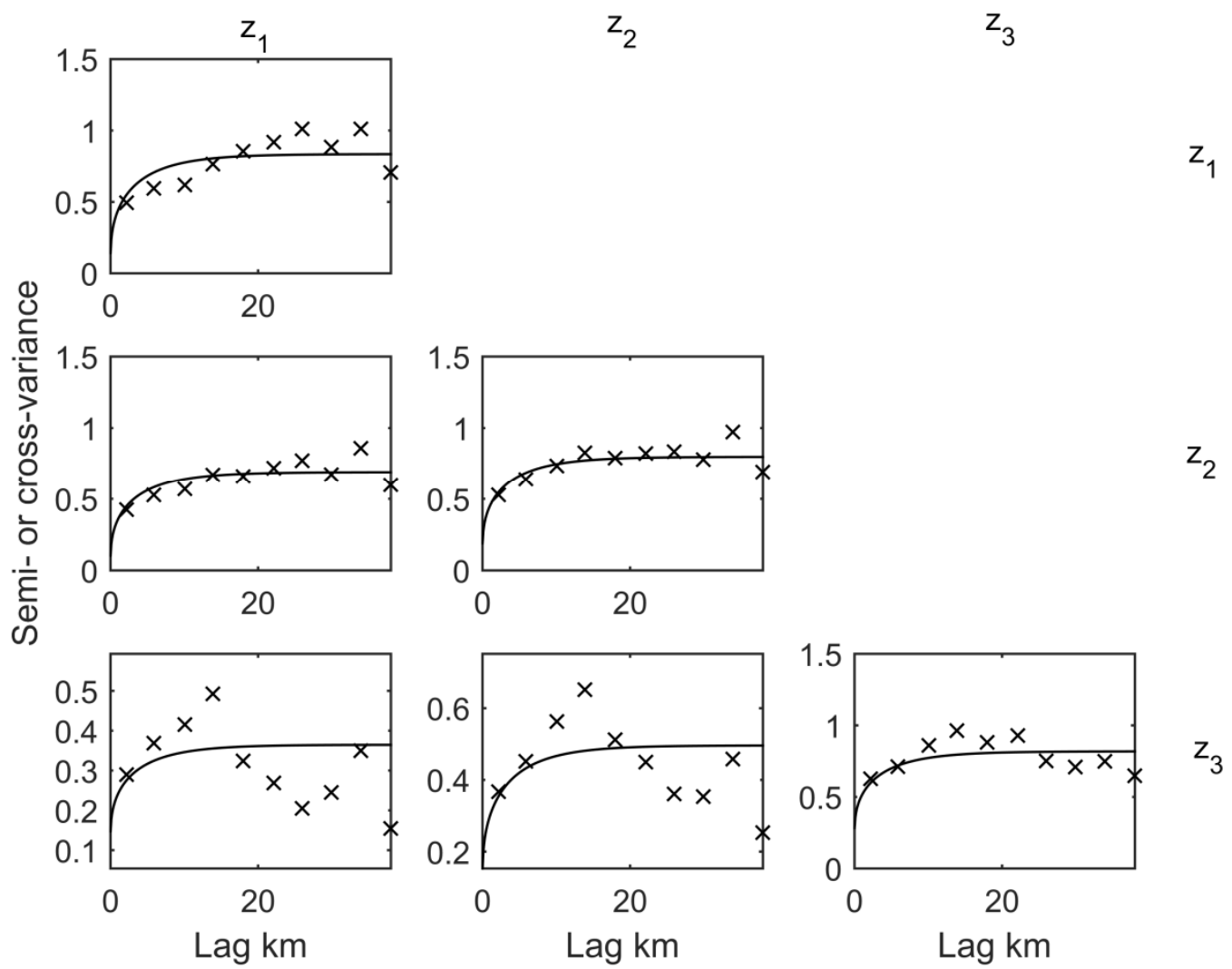

Fig. 10 Estimated horizontal variograms and cross-variograms for transformed variables $z_{1}, z_{2}$ and $z_{3}$. Crosses denote point estimate and continuous curves denote parametric models estimated by least squares. Variances are unit-less. 

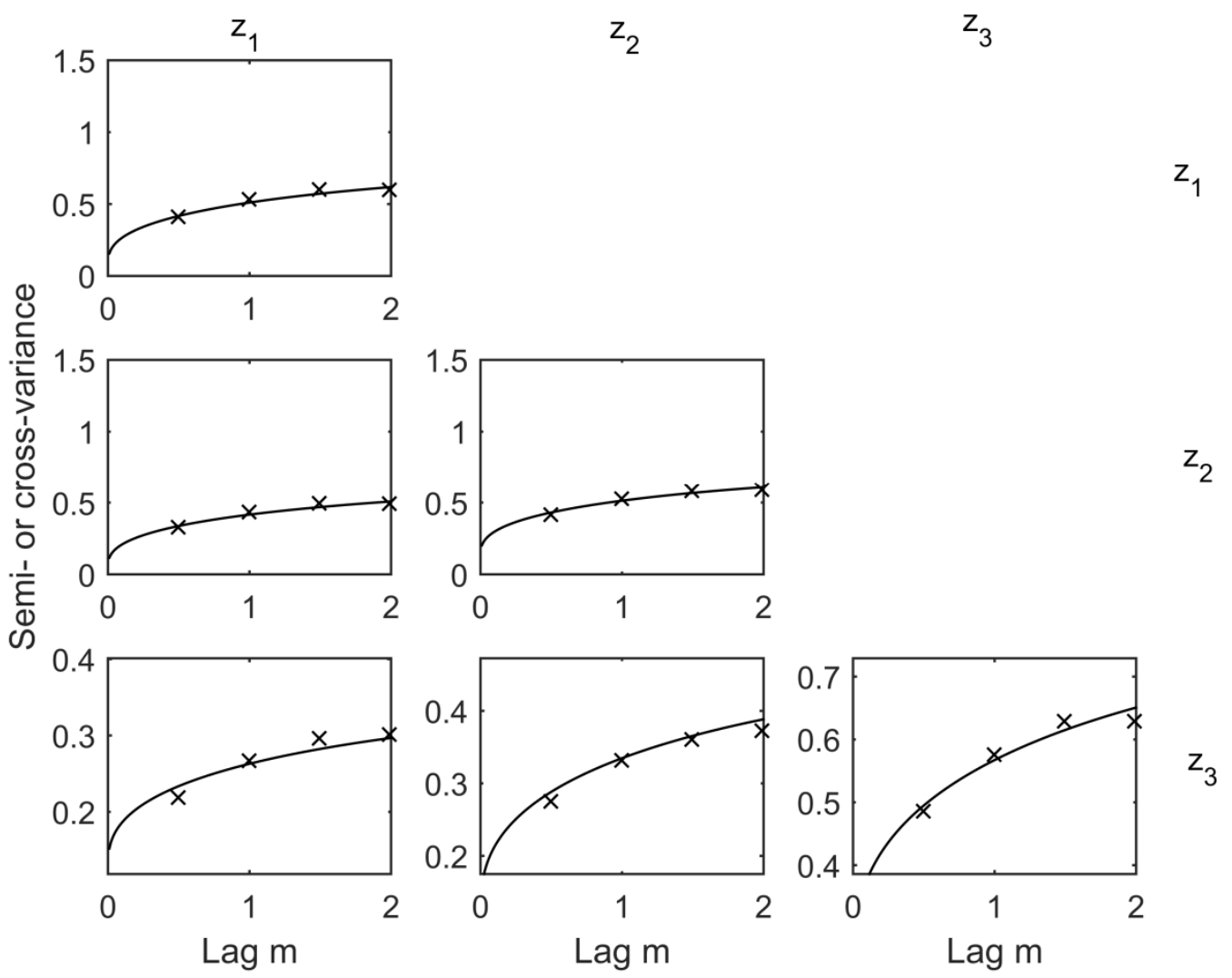

Fig. 11 Estimated vertical variograms and cross-variograms for transformed variables $z_{1}, z_{2}$ and $z_{3}$. Crosses denote point estimate and continuous curves denote parametric models estimated by least squares. Variances are unit-less. 

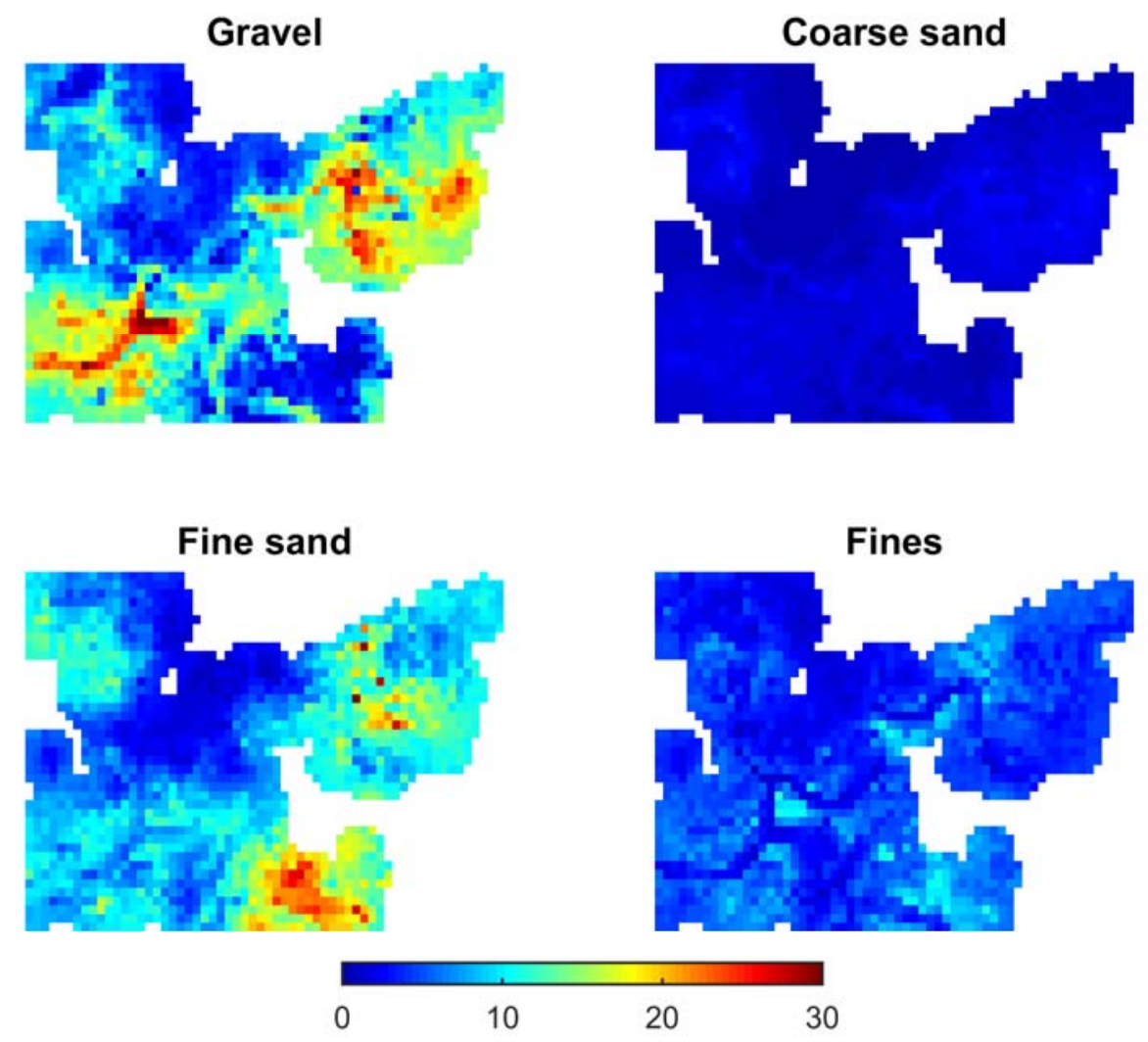

Fig. 12 Maps of estimated percentage of gravel, coarse sands, fine sands and fines to a depth of $5 \mathrm{~m}$. 


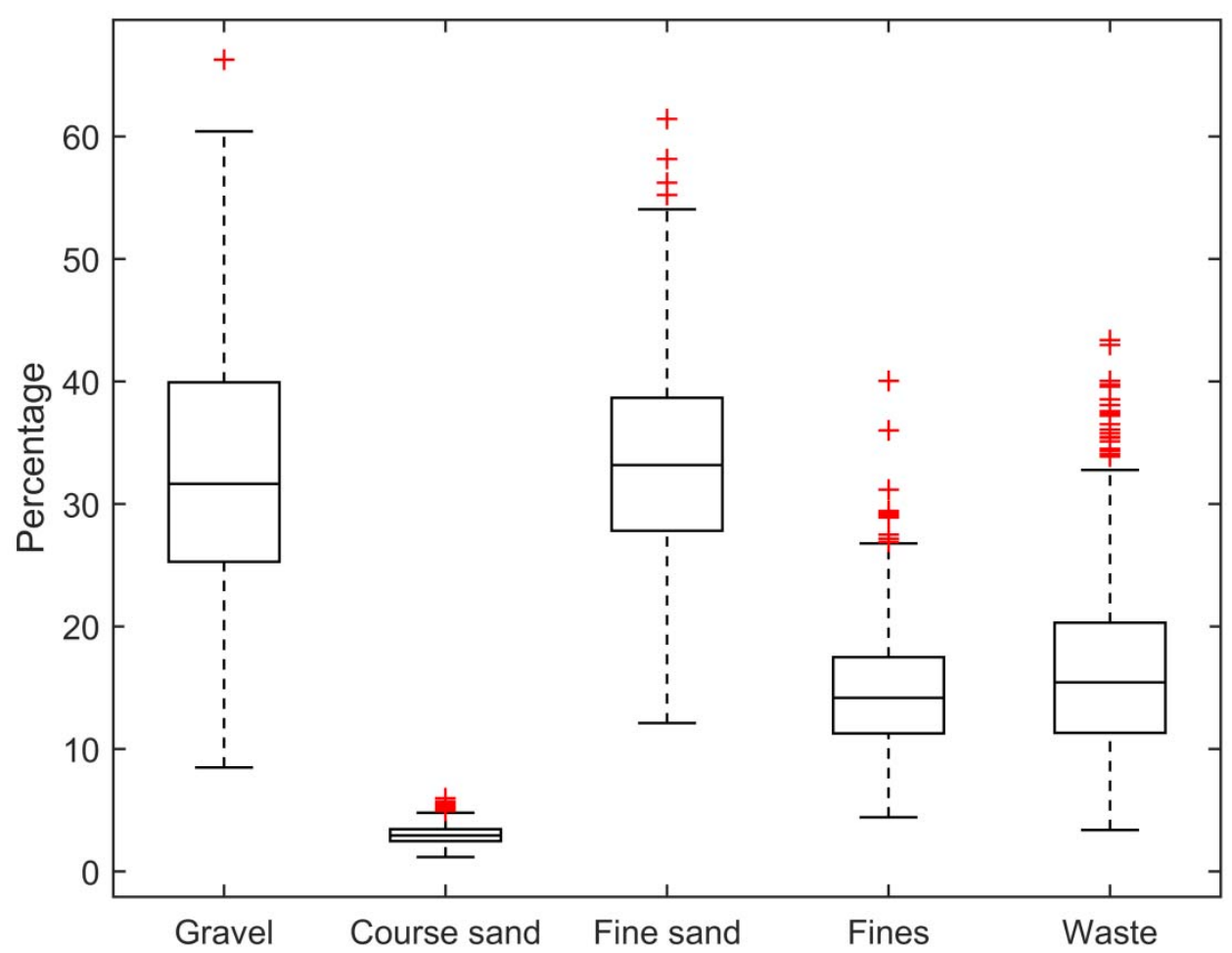

Fig. 13 Box-whisker plot showing the expected percentage and corresponding uncertainty of gravel, coarse sands, fine sands, fines and waste to a depth of $5 \mathrm{~m}$ below the location indicated by the red dot in Figure 5 . 


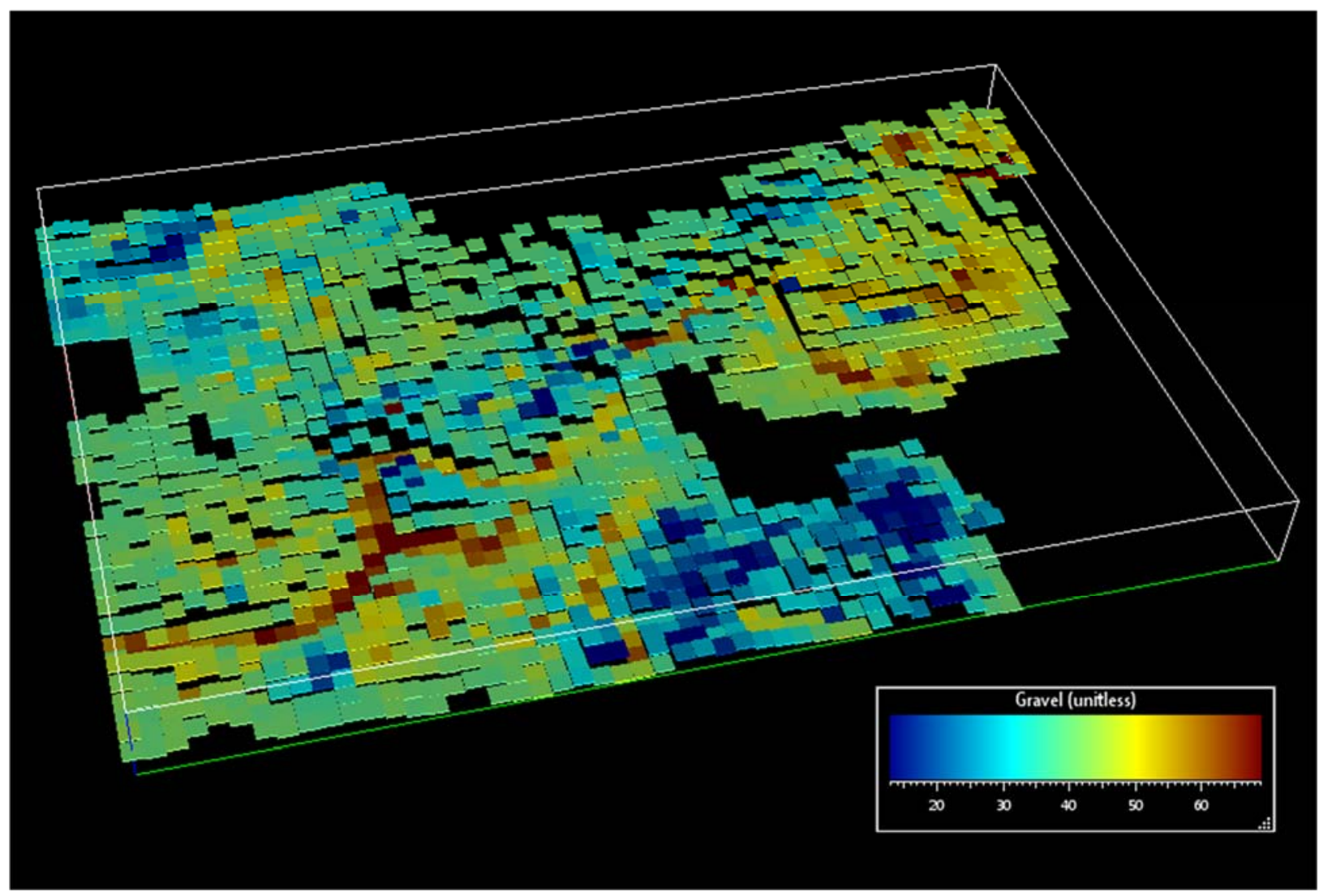

Fig. 14 3D model in GOCAD ${ }^{\mathrm{TM}}$ showing estimated percentage of gravel throughout the study area (vertical exaggeration is $\mathrm{x} 10$ ). 